\title{
Distribution of the Fukushima-derived radionuclides in seawater in the Pacific off the coast of Miyagi, Fukushima, and Ibaraki Prefectures, Japan
}

\author{
S. Oikawa, H. Takata, T. Watabe, J. Misonoo, and M. Kusakabe \\ Head Office, Marine Ecology Research Institute, Towa-Edogawabashi Building 7F, 347 Yamabuki-cho, Shinjuku, 162-0801 \\ Tokyo, Japan
}

Correspondence to: H. Takata (takata@kaiseiken.or.jp)

Received: 28 December 2012 - Published in Biogeosciences Discuss.: 11 March 2013

Revised: 18 June 2013 - Accepted: 3 July 2013 - Published: 25 July 2013

\begin{abstract}
The activities of artificial radionuclides in seawater samples collected off the coast of Miyagi, Fukushima, and Ibaraki Prefectures were measured as part of a monitoring program initiated by the Japanese Ministry of Education, Sports, Science and Technology immediately after the Fukushima Dai-ichi Nuclear Power Plant accident. The spatial and temporal distributions of those activities are summarized herein. The activities of strontium-90, iodine-131, cesium-134 and -137 (i.e. ${ }^{90} \mathrm{Sr},{ }^{131} \mathrm{I},{ }^{134} \mathrm{Cs}$, and ${ }^{137} \mathrm{Cs}$ ) derived from the accident were detected in seawater samples taken from areas of the coastal ocean adjacent to the power plant. No ${ }^{131}$ I was detected in surface waters $(\leq 5 \mathrm{~m}$ depth $)$ or in intermediate and bottom waters after 30 April 2011. Strontium-90 was found in surface waters collected from a few sampling stations in mid-August 2011 to mid-December 2011. Temporal changes of ${ }^{90} \mathrm{Sr}$ activity in surface waters were evident, although the ${ }^{90} \mathrm{Sr}$ activity at a given time varied widely between sampling stations. The activity of ${ }^{90} \mathrm{Sr}$ in surface waters decreased slowly over time, and by the end of December 2011 had reached background levels recorded before the accident. Radiocesium, ${ }^{134} \mathrm{Cs}$ and ${ }^{137} \mathrm{Cs}$, was found in seawater samples immediately after the accident. There was a remarkable change in radiocesium activities in surface waters during the first 7 months (March through September 2011) after the accident; the activity reached a maximum in the middle of April and thereafter decreased exponentially with time. Qualitatively, the distribution patterns in surface waters suggested that in early May radiocesium-polluted water was advected northward; some of the water then detached and was transported to the south. Two water cores with high
\end{abstract}

${ }^{137}$ Cs activity persisted at least until July 2011. In subsurface waters radiocesium activity was first detected in the beginning of April 2011, and the water masses were characterized by $\sigma_{t}$ (an indicator of density) values of 25.5-26.5. From 9-14 May to 5-16 December 2011, the depths of the water masses increased with time, an indication that deepening of the isopycnal surfaces with time can be an important mechanism for the transport of radiocesium downward in coastal waters. During 4-21 February 2012, the water column became vertically homogeneous, probably because of convective mixing during the winter; the result was nearly constant values of radiocesium activity throughout the water column from the surface to the bottom $(\sim 200 \mathrm{~m}$ depth $)$ at each station.

\section{Introduction}

At 14:46 JST (05:46 UTC) on 11 March 2011, the Great East Japan Earthquake (M9.0) and ensuing tsunami caused serious damage to the natural environment of Japan (JMA, 2011a, b). At the Tokyo Electric Power Company's Fukushima Dai-ichi Nuclear Power Plant (FDNPP) where three of six boiling water reactor units were operating, a series of very large tsunami waves damaged the electrical systems, and the external power supplies were lost because of the earthquake. Two emergency diesel electric generators then quickly started up, but all alternating current power supplies were lost after the two emergency generators had been 
stopped as a result of damage caused by a series of tsunami waves (NERH, 2011).

At 15:36 JST (06:36 UTC) on the day following the accident, a hydrogen explosion occurred in the Unit 1 reactor building as a consequence of the failure of the reactor cooling system. On 14 March a hydrogen explosion also occurred in the Unit 3 reactor building. Although the Unit 4 reactor had been shut down for planned maintenance and its fuel rods were in the spent fuel pool at the time of the earthquake, an explosion occurred in the Unit 4 reactor building on 15 March. On the same day, an explosion that occurred in the Unit 2 reactor caused a reduction of pressure in the suppression pool at the bottom of its containment vessel. The explosions resulted in the release of large amounts of radioactive materials into the environment. The Japanese Government estimated the amounts of ${ }^{131} \mathrm{I},{ }^{134} \mathrm{Cs}$, and ${ }^{137} \mathrm{Cs}$ released into the atmosphere to be 160,18 , and $15 \mathrm{PBq}$, respectively, from 11 March to 5 April 2011 (NERH, 2011). Results of environmental monitoring suggested that ${ }^{131} \mathrm{I}$ and ${ }^{137} \mathrm{Cs}$ derived from the FDNPP were observed within three days after the accident in airborne dust at Fukuoka Prefecture, western Japan, more than $1000 \mathrm{~km}$ from the FDNPP (Momoshima et al., 2012). In the early stage of the accident, large amounts of wastewater had accumulated at the sites of the Unit 1,2, and 3 reactors because of the use of large volumes of cooling water to prevent the occurrence of a more serious nuclear accident. Although the total volume of highly contaminated wastewater is still unknown, significant amounts of water that accumulated in the reactor buildings have leaked out through underground conduits into the ocean (Kawamura et al., 2011; Tsumune et al., 2012). From numerical simulations, Tsumune et al. (2012) estimated the total amount of ${ }^{137} \mathrm{Cs}$ released directly into the ocean from 26 March 2011 to be $3.5 \pm 0.7 \mathrm{PBq}$.

About ten days after the accident, the Marine Ecology Research Institute started an environmental radioactivity monitoring study, with a particular focus on the offshore ocean, by taking seawater samples and performing analyses of radioactivity. In response to changes in societal concerns, the monitored area of the ocean has been expanded progressively since that time. The radioactivity data obtained during the monitoring program have been published on the website of the Ministry of Education, Culture, Sports, Science and Technology (MEXT) (http://radioactivity.mext.go.jp/en/ list/259/list-1.html). In this paper, we compile and revise, when necessary and if possible, the data on ${ }^{90} \mathrm{Sr},{ }^{131} \mathrm{I},{ }^{134} \mathrm{Cs}$, and ${ }^{137} \mathrm{Cs}$ activities in seawater samples collected outside the area, beginning at a $30 \mathrm{~km}$ radius from the plant, off the coast of Miyagi, Fukushima, and Ibaraki Prefectures immediately after the FDNPP accident. A special revision was made for the radioactivity data on the MEXT website that lacked error information. Furthermore, we conducted re-analysis of radiocesium activity derived from the AMP method instead of the direct measurement. For example, on the Nuclear Regulation Authority (NRA) web page (http://radioactivity.nsr. go.jp/ja/list/273/list-1.html), the radiocesium activities in all the samples are reported as "not detectable (less than about 6-9 $\mathrm{BqL}^{-1}$ )" while we report the activities in $\mathrm{mBqL}^{-1}$ in surface and subsurface samples in this paper. We furthermore describe the spatiotemporal variations of the radiocesium activities in seawater samples collected every two months from the coastal ocean east of Japan during the time immediately after the accident until the end of February 2012. We investigated the mechanisms that control the movement of ${ }^{137} \mathrm{Cs}$ in the water column from the surface to the bottom together with data of other complementary parameters which are not available on the MEXT website, including salinity, temperature, and $\sigma_{t}$, an indicator of density of a given temperature. Thus, we elucidate the influence of oceanic processes on radionuclide behavior in the coastal waters using the parameters.

Activities of ${ }^{137} \mathrm{Cs}$ in surface seawaters after the accident have been reported (Aoyama et al., 2012; Buesseler et al., 2012; Honda et al., 2012). These reports indicate that the ${ }^{137} \mathrm{Cs}$ that originated from the FDNPP migrated as far as $\sim 600 \mathrm{~km}$ from the shore because of near-shore eddies and the Kuroshio Current as well as airborne transportation. In the subsurface waters, elevated ${ }^{137} \mathrm{Cs}$ activities have also been observed (Buesseler et al., 2012). However, the vertical transport mechanisms for radiocesium in the area are not fully understood. In general, two main processes are thought to transport radiocesium downward: (1) sinking particles and (2) water mixing (e.g., diapycnal and isopycnal mixing). Before the FDNPP accident, the main source of radiocesium in seawater in the North Pacific had been fallout from past nuclear weapons tests and the Chernobyl accident (Oikawa et al., 2011). In those cases, radiocesium was deposited onto the sea surface from the atmosphere and then transported downward by sinking particles (Fowler et al., 1987; Kusakabe et al., 1988). For example, ${ }^{134} \mathrm{Cs}$ and ${ }^{137} \mathrm{Cs}$ that originated from the Chernobyl accident were detected in sediment traps deployed at depths of $110-780 \mathrm{~m}$ in the North Pacific and Bering Sea within a few months after the accident (Kusakabe et al., 1988). In the case of the FDNPP accident, both the atmospheric deposition and the direct discharge of wastewater were important sources in seawaters off the coast of Miyagi, Fukushima, and Ibaraki Prefectures. Only two-three months after the accident, FDNPP-derived nuclides were observed in subsurface waters (Buesseler et al., 2012) where ${ }^{137}$ Cs activities were about 100 times higher than the values before the accident (Oikawa et al., 2013). It is unlikely that transport of radiocesium downward by only sinking particles occurred (see Sect. 3.2.2). These results indicate that FDNPP-derived nuclides were transported downward by vertical water mixing as well as sinking particles. As for the vertical water mixing, the diapycnal mixing in these coastal areas is mainly affected by diurnal tidal currents during the spring and autumn. It has been reported that the vertically homogeneous physical structure of the water column (i.e., $\sigma_{t}$, salinity, and temperature) results from vigorous vertical mixing of the water 
column during periods of strong tidal currents (see e.g., Matsuura et al., 2007). In addition, during winter, the vertical distributions of temperature, salinity, $\sigma_{t}$, and other properties (e.g., nutrient concentrations) indicate that the surface waters are well mixed to depths ranging from one to several hundred meters (Yoshie et al., 2003). Furthermore, the mixing of radiocesium along isopycnal surfaces could be important. If the isopycnal surfaces deepen, for example, activity in radiocesium can be diluted along the surfaces, resulting in the appearance of radiocesium at subsurface waters. Thus, discussion of these two processes (i.e. transportation by sinking particles and water mixing) is a key to better understanding radiocesium behavior in the coastal seawaters off Miyagi, Fukushima, and Ibaraki Prefectures.

\section{Materials and methods}

\subsection{Survey areas and sampling}

The survey areas are shown in Fig. 1. Seawater samples were collected from the surface ( $\leq 5 \mathrm{~m}$ depth) to near the bottom ( $\sim 30 \mathrm{~m}$ above the seafloor) at each sampling station (Table 1). To elucidate the spatiotemporal distribution of the artificial radionuclides, the number of sampling stations increased as the monitoring study progressed. The monitoring area was also expanded accordingly. Thus, the sampling period of $1 \mathrm{yr}$ was divided into two phases as described next.

\subsubsection{Phase 1 (23 March 2011 to 7 May 2011)}

The first cruise (KH11-E01) for Phase 1 commenced on 23 March 2011 and then three other cruises (MR11-E01, KR11E02 and YK11-E02) followed until 7 May 2011. Since the objective of the first phase was to detect radionuclides released from the FDNPP, samples were collected from only eight sampling stations (1-1 to 1-4 and 2-1 to 2-4) located in the western North Pacific Ocean $30 \mathrm{~km}$ off the coast from the FDNPP. In the middle of the survey period, we added several more stations (i.e. 2-5, 2-6, 1-A, 1-B, S1, S2, S3 and S4) so that the stations formed a U-shape surrounding the FDNPP. We used a Niskin-type water sampler with a CTD system (SBE 9 plus, Sea-Bird Electronics, Inc., Bellevue, WA, USA) to collect water samples. Because of the urgent nature of the survey, during Phase $1,500 \mathrm{~mL}$ or $20 \mathrm{~L}$ of seawater samples were collected at each station. The samples were returned to a laboratory without addition of any acids.

\subsubsection{Phase 2 (9 May 2011 to the end of February 2012)}

On 9 May 2011, Phase 2 was implemented by expanding the sampling area in the western North Pacific Ocean (Fig. 1c). Seawater samples were taken from 2,3 , and 4 depths, namely the surface ( $\leq 5 \mathrm{~m}$ depth), intermediate, and bottom depths. During Phase 2, we used a Van Dorn-type or Niskin-type water sampler with a CTD system (SBE 19, Sea-Bird Electron- ics, Inc.). Bottom water samples were collected at $\leq 30 \mathrm{~m}$ above the seabed. The intermediate water samples were obtained between the surface and bottom at variable depths depending on the water depth of the individual stations.

\subsection{Radioactivity measurements}

\subsection{1 ${ }^{131} \mathrm{I},{ }^{134} \mathrm{Cs}$, and ${ }^{137} \mathrm{Cs}$ measurements}

Aliquots (0.5-2 L) of seawater samples taken during Phase 1 were put into a Marinelli container and their radioactivities were measured for several tens of minutes using a gammaray spectrometer with a coaxial Ge detector.

From samples taken in the following cruises during Phase 2, NT11-E01, NT11-E02, MR11-E02, YK11-E03, YK11-E05, and KR11-E04 and bottom water samples and some surface samples in 11WM01-11WM06, $2 \mathrm{~L}$ aliquots of seawater were used to measure radioactivity by the same method as above. For the remaining sample volumes collected during Phase 2, $2 \mathrm{~L}$ or $40-60 \mathrm{~L}$ was used for the radiocesium analyses. After adjusting the $\mathrm{pH}$ of the seawater sample to nearly 1 with hydrochloric acid, cesium was coprecipitated with ammonium phosphomolybdate (AMP; Kishida Chemical Co., Ltd.). The recovery of Cs with AMP was obtained gravimetrically. For example, we got a recovery of $96.8 \%$ on average for samples in the KY11-E03 cruise. The activity of radiocesium $\left({ }^{134} \mathrm{Cs}\right.$ and $\left.{ }^{137} \mathrm{Cs}\right)$ coprecipitated with AMP was measured with coaxial-type Ge detectors (Canberra GC40 series, relative efficiency $=40 \%$, and Eurisys EGPC series, relative efficiency $=89 \%$, Canberra Japan KK) for a few hours. The supernatant of the AMP precipitation was used for the determination of ${ }^{90} \mathrm{Sr}$. Inoue et al. (2012) have pointed out that the cascade summing effect should not be disregarded for the 604.7 and $795.8 \mathrm{keV}$ photopeaks emitted from ${ }^{134} \mathrm{Cs}$ when measurements are carried out with the sample close to the Ge detector. In our measurements, based on the peak / total ratio method (MEXT, 1992) the cascade summing of ${ }^{134} \mathrm{Cs}$ in all samples was corrected using computer software (e.g., Gamma Explorer, Canberra Japan KK). The detection limits of ${ }^{134} \mathrm{Cs}$ and ${ }^{137} \mathrm{Cs}$ were calculated based on three times the value of the counting statistics error, the minimum detectable activities of ${ }^{134} \mathrm{Cs}$ and ${ }^{137} \mathrm{Cs}$ were expected to be $0.1-1.0 \mathrm{mBq} \mathrm{L}^{-1}$ for counting times of tens of thousands of seconds. The radioactivities of ${ }^{134} \mathrm{Cs}$ and ${ }^{137} \mathrm{Cs}$ in the water samples were decay-corrected to the sampling date.

\subsection{2 ${ }^{90} \mathrm{Sr}$ measurements}

When measuring ${ }^{90} \mathrm{Sr}$ in the water samples, we used the same water samples as were used for the radiocesium measurements. The supernatant of the AMP precipitation was passed through a cation exchange resin column (Dowex 50W-X8, 100-200 mesh, $9 \mathrm{~cm} \varphi \times 32 \mathrm{~cm}$ ) to remove $\mathrm{Mg}$, one of the elements in seawater that would interfere with the analysis. 


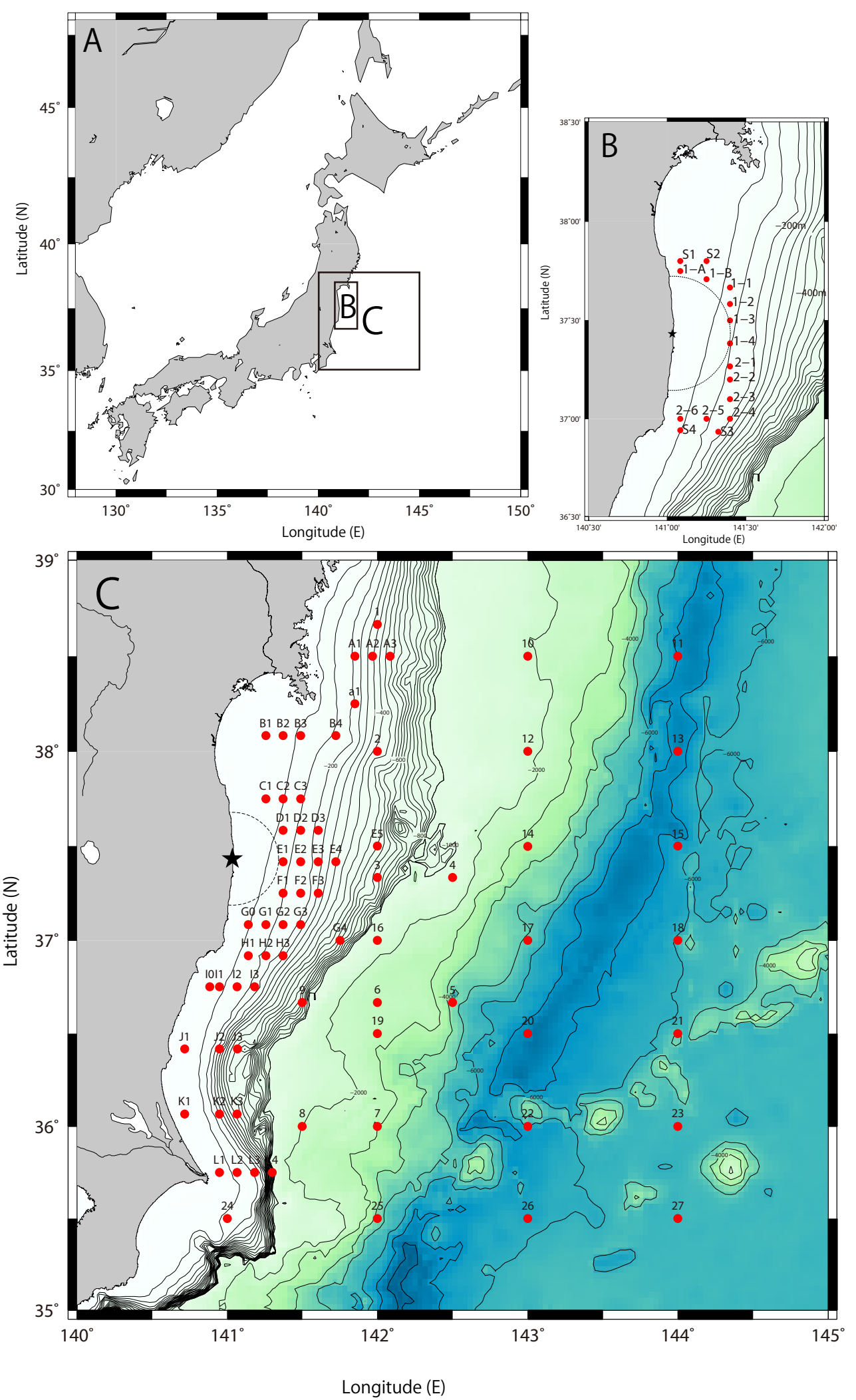

Fig. 1. Locations of sampling areas in coastal areas off Fukushima, Japan (A) and sampling stations during Phase 1 (23 March 2011 to 7 May 2011) (B) and Phase 2 (9 May 2011 to 21 February 2012) (C). 
Table 1. Sampling stations during the two phases (sampling date: JST).

\begin{tabular}{lccccr}
\hline Station & $\begin{array}{c}\text { Latitude } \\
(\mathrm{N})\end{array}$ & $\begin{array}{c}\text { Longitude } \\
\text { (E) }\end{array}$ & \multicolumn{3}{c}{ Depth $(\mathrm{m})^{*}$} \\
Min. & - & Max. \\
\hline 23 Mar 2011 to 7 May 2011 (Phase 1) & & \\
$1-1$ & $37^{\circ} 40.0^{\prime}$ & $141^{\circ} 24.0^{\prime}$ & 125 & - & 137 \\
$1-2$ & $37^{\circ} 35.0^{\prime}$ & $141^{\circ} 24.0^{\prime}$ & 131 & - & 133 \\
$1-3$ & $37^{\circ} 30.0^{\prime}$ & $141^{\circ} 24.0^{\prime}$ & 134 & - & 135 \\
$1-4$ & $37^{\circ} 23.0^{\prime}$ & $141^{\circ} 24.0^{\prime}$ & 140 & - & 142 \\
$2-1$ & $37^{\circ} 16.0^{\prime}$ & $141^{\circ} 24.0^{\prime}$ & 148 & - & 150 \\
$2-2$ & $37^{\circ} 12.0^{\prime}$ & $141^{\circ} 24.0^{\prime}$ & 150 & - & 152 \\
$2-3$ & $37^{\circ} 06.0^{\prime}$ & $141^{\circ} 24.0^{\prime}$ & 171 & - & 173 \\
$2-4$ & $37^{\circ} 00.0^{\prime}$ & $141^{\circ} 24.0^{\prime}$ & 182 & - & 186 \\
$2-5$ & $37^{\circ} 00.0^{\prime}$ & $141^{\circ} 15.0^{\prime}$ & 146 & - & 147 \\
$2-6$ & $37^{\circ} 00.0^{\prime}$ & $141^{\circ} 05.0^{\prime}$ & 101 & - & 103 \\
$1-A$ & $37^{\circ} 45.0^{\prime}$ & $141^{\circ} 05.0^{\prime}$ & 25 & - & 32 \\
$1-B$ & $37^{\circ} 42.5^{\prime}$ & $141^{\circ} 15.0^{\prime}$ & & 61 & \\
S1 & $37^{\circ} 48.0^{\prime}$ & $141^{\circ} 05.0^{\prime}$ & & & \\
S2 & $37^{\circ} 48.0^{\prime}$ & $141^{\circ} 15.0^{\prime}$ & & & \\
S3 & $36^{\circ} 56.0^{\prime}$ & $141^{\circ} 19.5^{\prime}$ & & & \\
S4 & $36^{\circ} 56.5^{\prime}$ & $141^{\circ} 05.0^{\prime}$ & &
\end{tabular}

9 May 2011 to 21 Feb 2012 (Phase 2)

\begin{tabular}{|c|c|c|c|c|c|}
\hline 1 & $38^{\circ} 40.0^{\prime}$ & $142^{\circ} 00.0^{\prime}$ & 327 & - & 341 \\
\hline 2 & $38^{\circ} 00.0^{\prime}$ & $142^{\circ} 00.0^{\prime}$ & 361 & - & 373 \\
\hline 3 & $37^{\circ} 20.0^{\prime}$ & $142^{\circ} 00.0^{\prime}$ & 691 & - & 744 \\
\hline 4 & $37^{\circ} 20.0^{\prime}$ & $142^{\circ} 30.0^{\prime}$ & 211 & - & 1210 \\
\hline 5 & $36^{\circ} 40.0^{\prime}$ & $142^{\circ} 30.0^{\prime}$ & 3477 & - & 4379 \\
\hline 6 & $36^{\circ} 40.0^{\prime}$ & $142^{\circ} 00.0^{\prime}$ & 2474 & - & 2492 \\
\hline 7 & $36^{\circ} 00.0^{\prime}$ & $142^{\circ} 00.0^{\prime}$ & 3105 & - & 3430 \\
\hline 8 & $36^{\circ} 00.0^{\prime}$ & $141^{\circ} 30.0^{\prime}$ & 1970 & - & 2215 \\
\hline 9 & $36^{\circ} 40.0^{\prime}$ & $141^{\circ} 30.0^{\prime}$ & 798 & - & 864 \\
\hline 10 & $38^{\circ} 30.0^{\prime}$ & $143^{\circ} 00.0^{\prime}$ & & 1737 & \\
\hline 11 & $38^{\circ} 30.0^{\prime}$ & $144^{\circ} 00.0^{\prime}$ & & 7282 & \\
\hline 12 & $38^{\circ} 00.0^{\prime}$ & $143^{\circ} 00.0^{\prime}$ & & 1854 & \\
\hline 13 & $38^{\circ} 00.0^{\prime}$ & $144^{\circ} 00.0^{\prime}$ & & 7567 & \\
\hline 14 & $37^{\circ} 30.0^{\prime}$ & $143^{\circ} 00.0^{\prime}$ & & 3264 & \\
\hline 15 & $37^{\circ} 30.0^{\prime}$ & $144^{\circ} 00.0^{\prime}$ & & 6798 & \\
\hline 16 & $37^{\circ} 00.0^{\prime}$ & $142^{\circ} 00.0^{\prime}$ & & 1360 & \\
\hline 17 & $37^{\circ} 00.0^{\prime}$ & $143^{\circ} 00.0^{\prime}$ & & 5108 & \\
\hline 18 & $37^{\circ} 00.0^{\prime}$ & $144^{\circ} 00.0^{\prime}$ & & 6161 & \\
\hline 19 & $36^{\circ} 30.0^{\prime}$ & $142^{\circ} 00.0^{\prime}$ & & 2755 & \\
\hline 20 & $36^{\circ} 30.0^{\prime}$ & $143^{\circ} 00.0^{\prime}$ & & 7282 & \\
\hline 21 & $36^{\circ} 30.0^{\prime}$ & $144^{\circ} 00.0^{\prime}$ & & 5846 & \\
\hline 22 & $36^{\circ} 00.0^{\prime}$ & $143^{\circ} 00.0^{\prime}$ & & 5971 & \\
\hline 23 & $36^{\circ} 00.0^{\prime}$ & $144^{\circ} 00.0^{\prime}$ & & 5836 & \\
\hline 24 & $35^{\circ} 30.0^{\prime}$ & $141^{\circ} 00.0^{\prime}$ & & 120 & \\
\hline 25 & $35^{\circ} 30.0^{\prime}$ & $142^{\circ} 00.0^{\prime}$ & & 4572 & \\
\hline 26 & $35^{\circ} 30.0^{\prime}$ & $143^{\circ} 00.0^{\prime}$ & & 6228 & \\
\hline 27 & $35^{\circ} 30.0^{\prime}$ & $144^{\circ} 00.0^{\prime}$ & & 5761 & \\
\hline A1 & $38^{\circ} 30.0^{\prime}$ & $141^{\circ} 51.0^{\prime}$ & 202 & - & 212 \\
\hline a1 & $38^{\circ} 15.0^{\prime}$ & $141^{\circ} 51.0^{\prime}$ & 212 & - & 218 \\
\hline A2 & $38^{\circ} 30.0^{\prime}$ & $141^{\circ} 58.0^{\prime}$ & 302 & - & 314 \\
\hline A3 & $38^{\circ} 30.0^{\prime}$ & $142^{\circ} 05.0^{\prime}$ & 468 & - & 498 \\
\hline B1 & $38^{\circ} 05.0^{\prime}$ & $141^{\circ} 15.4^{\prime}$ & 44 & - & 45 \\
\hline
\end{tabular}

Table 1. Continued.

\begin{tabular}{|c|c|c|c|c|c|}
\hline \multirow[t]{2}{*}{ Station } & \multirow{2}{*}{$\begin{array}{l}\text { Latitude } \\
(\mathrm{N})\end{array}$} & \multirow{2}{*}{$\begin{array}{l}\text { Longitude } \\
\text { (E) }\end{array}$} & \multicolumn{3}{|c|}{ Depth $(\mathrm{m})^{*}$} \\
\hline & & & Min. & - & Max. \\
\hline B2 & $38^{\circ} 05.0^{\prime}$ & $141^{\circ} 22.4^{\prime}$ & 74 & - & 76 \\
\hline B3 & $38^{\circ} 05.0^{\prime}$ & $141^{\circ} 29.4^{\prime}$ & 118 & - & 122 \\
\hline B4 & $38^{\circ} 05.0^{\prime}$ & $141^{\circ} 43.4^{\prime}$ & 156 & - & 161 \\
\hline $\mathrm{C} 1$ & $37^{\circ} 45.0^{\prime}$ & $141^{\circ} 15.4^{\prime}$ & 55 & - & 59 \\
\hline $\mathrm{C} 2$ & $37^{\circ} 45.0^{\prime}$ & $141^{\circ} 22.4^{\prime}$ & 104 & - & 109 \\
\hline $\mathrm{C} 3$ & $37^{\circ} 45.0^{\prime}$ & $141^{\circ} 29.4^{\prime}$ & 133 & - & 137 \\
\hline D1 & $37^{\circ} 35.0^{\prime}$ & $141^{\circ} 22.4^{\prime}$ & 123 & - & 127 \\
\hline D2 & $37^{\circ} 35.0^{\prime}$ & $141^{\circ} 29.4^{\prime}$ & 135 & - & 138 \\
\hline D3 & $37^{\circ} 35.0^{\prime}$ & $141^{\circ} 36.4^{\prime}$ & 222 & - & 230 \\
\hline E1 & $37^{\circ} 25.0^{\prime}$ & $141^{\circ} 22.4^{\prime}$ & 132 & - & 138 \\
\hline E2 & $37^{\circ} 25.0^{\prime}$ & $141^{\circ} 29.4^{\prime}$ & 153 & - & 157 \\
\hline E3 & $37^{\circ} 25.0^{\prime}$ & $141^{\circ} 36.4^{\prime}$ & 228 & - & 243 \\
\hline E4 & $37^{\circ} 25.0^{\prime}$ & $141^{\circ} 43.4^{\prime}$ & 338 & - & 352 \\
\hline E5 & $37^{\circ} 30.0^{\prime}$ & $142^{\circ} 00.0^{\prime}$ & 531 & - & 556 \\
\hline $\mathrm{F} 1$ & $37^{\circ} 15.0^{\prime}$ & $141^{\circ} 22.4^{\prime}$ & 139 & - & 146 \\
\hline $\mathrm{F} 2$ & $37^{\circ} 15.0^{\prime}$ & $141^{\circ} 29.4^{\prime}$ & 172 & - & 175 \\
\hline F3 & $37^{\circ} 15.0^{\prime}$ & $141^{\circ} 36.4^{\prime}$ & 230 & - & 248 \\
\hline G0 & $37^{\circ} 05.0^{\prime}$ & $141^{\circ} 08.4^{\prime}$ & 107 & - & 110 \\
\hline G1 & $37^{\circ} 05.0^{\prime}$ & $141^{\circ} 15.4^{\prime}$ & 138 & - & 142 \\
\hline $\mathrm{G} 2$ & $37^{\circ} 05.0^{\prime}$ & $141^{\circ} 22.4^{\prime}$ & 161 & - & 166 \\
\hline G3 & $37^{\circ} 05.0^{\prime}$ & $141^{\circ} 29.4^{\prime}$ & 205 & - & 216 \\
\hline G4 & $37^{\circ} 00.0^{\prime}$ & $141^{\circ} 45.0^{\prime}$ & 655 & - & 683 \\
\hline H1 & $36^{\circ} 55.0^{\prime}$ & $141^{\circ} 08.4^{\prime}$ & 130 & - & 137 \\
\hline $\mathrm{H} 2$ & $36^{\circ} 55.0^{\prime}$ & $141^{\circ} 15.4^{\prime}$ & 152 & - & 158 \\
\hline H3 & $36^{\circ} 55.0^{\prime}$ & $141^{\circ} 22.4^{\prime}$ & 231 & - & 241 \\
\hline I0 & $36^{\circ} 45.0^{\prime}$ & $140^{\circ} 53.0^{\prime}$ & 72 & - & 73 \\
\hline I1 & $36^{\circ} 45.0^{\prime}$ & $140^{\circ} 57.0^{\prime}$ & 94 & - & 101 \\
\hline $\mathrm{I} 2$ & $36^{\circ} 45.0^{\prime}$ & $141^{\circ} 04.0^{\prime}$ & 131 & - & 138 \\
\hline I3 & $36^{\circ} 45.0^{\prime}$ & $141^{\circ} 11.0^{\prime}$ & 181 & - & 195 \\
\hline $\mathrm{J} 1$ & $36^{\circ} 25.0^{\prime}$ & $140^{\circ} 43.0^{\prime}$ & 43 & - & 50 \\
\hline $\mathrm{J} 2$ & $36^{\circ} 25.0^{\prime}$ & $140^{\circ} 57.0^{\prime}$ & 280 & - & 302 \\
\hline $\mathrm{J} 3$ & $36^{\circ} 25.0^{\prime}$ & $141^{\circ} 04.1^{\prime}$ & 530 & - & 589 \\
\hline $\mathrm{K} 1$ & $36^{\circ} 04.0^{\prime}$ & $140^{\circ} 43.0^{\prime}$ & 23 & - & 33 \\
\hline $\mathrm{K} 2$ & $36^{\circ} 04.0^{\prime}$ & $140^{\circ} 57.0^{\prime}$ & 193 & - & 215 \\
\hline K3 & $36^{\circ} 04.0^{\prime}$ & $141^{\circ} 04.0^{\prime}$ & 470 & - & 499 \\
\hline L1 & $35^{\circ} 45.0^{\prime}$ & $140^{\circ} 57.0^{\prime}$ & 36 & - & 45 \\
\hline L2 & $35^{\circ} 45.0^{\prime}$ & $141^{\circ} 04.0^{\prime}$ & 105 & - & 113 \\
\hline L3 & $35^{\circ} 45.0^{\prime}$ & $141^{\circ} 11.0^{\prime}$ & 140 & - & 172 \\
\hline L4 & $35^{\circ} 45.0^{\prime}$ & $141^{\circ} 18.0^{\prime}$ & 640 & - & 850 \\
\hline
\end{tabular}

* Because stations during each cruise were located within 1 nautical mile from a certain point based on a GPS system, depth for each station varied a little. For detailed information on cruises and sampling stations, see Table 1 in the Supplement.

After the addition of sodium carbonate, the $\mathrm{pH}$ of the seawater sample was adjusted to 8 with a solution of sodium hydroxide to co-precipitate $\mathrm{Sr}$ together with carbonate precipitates. The precipitates thus formed were boiled for approximately $2 \mathrm{~h}$ before being allowed to settle overnight. The sample supernatant was carefully decanted and discarded, and the carbonate precipitate was separated from the solution by centrifugation. The precipitate was dissolved in $1 \mathrm{M}$ hydrochloric acid and evaporated to dryness. The residue 
was dissolved in dilute hydrochloric acid and passed through a cation exchange resin column (Dowex 50W-X8, 100-200 mesh, $3 \mathrm{~cm} \varphi \times 26 \mathrm{~cm}$ ) for the complete removal of $\mathrm{Ca}$. The activity of ${ }^{90} \mathrm{Sr}$ was determined by using a gas-flow-type low background anti-coincidence beta counter (e.g., LBC-471Q, Aloka Co. Ltd., Japan) to count the beta rays emitted from ${ }^{90} \mathrm{Y}$ at radio-equilibrium with ${ }^{90} \mathrm{Sr}$. The detection limit of ${ }^{90} \mathrm{Sr}$ radioactivity, taken as three times the value of its counting statistics error, was about $0.4 \mathrm{mBqL}^{-1}$ with a $100 \mathrm{~min}$ counting time for a $50 \mathrm{~L}$ seawater sample.

\section{Results and discussion}

\subsection{Activities of ${ }^{131} \mathrm{I},{ }^{134} \mathrm{Cs}$, and ${ }^{137} \mathrm{Cs}$ in seawater (Phase 1)}

The activities of ${ }^{131} \mathrm{I},{ }^{134} \mathrm{Cs}$ and ${ }^{137} \mathrm{Cs}$ in the samples are summarized in Table 2 together with the ${ }^{131} \mathrm{I} /{ }^{137} \mathrm{Cs}$ and ${ }^{134} \mathrm{Cs} /{ }^{137} \mathrm{Cs}$ activity ratios.

Activities of ${ }^{131} \mathrm{I}$ were first detected in the surface water samples $(\leq 5 \mathrm{~m}$ depth) collected during the first cruise (KH11-E01) from 23-27 March. After that, they varied considerably compared to those of radiocesium. They decreased rapidly from a geometric mean of $39.2 \mathrm{~Bq} \mathrm{~L}^{-1}$ on 23 March 2011 to $7.0 \mathrm{~Bq} \mathrm{~L}^{-1}$ on 1 April 2011, and then increased again to $34.1-161 \mathrm{~Bq} \mathrm{~L}^{-1}$ in the middle of April. After that, they decreased again until the end of April 2011 (Fig. 2a). The ${ }^{131} \mathrm{I} /{ }^{137} \mathrm{Cs}$ activity ratios were scattered in the period from 23 March to 3 April 2011. After 9 April 2011, the ratio seemed to be converging to a value that followed its decay line. The variability of ${ }^{131} \mathrm{I}$ activity and its ratio to ${ }^{137} \mathrm{Cs}$ in surface water reflect variable contributions from the direct discharge of polluted waters and airborne dust (Chino et al., 2011) from the FDNPP, both which have different activity ratios from each other (see Fig. 11 in a companion paper of this issue by Kusakabe et al. 2013). Tsumune et al. (2012) inferred that although both nuclides in the area were derived mainly from the atmosphere until 9 April 2011, they were dominated by the direct discharge after that date.

The ${ }^{137} \mathrm{Cs}$ activities in surface waters are monitored for $28 \mathrm{yr}$ as part of a nationwide surveillance project begun before the accident; these were fixed sampling stations that are approximately $6 \mathrm{~km}$ east of the sampling stations in Fig. $1 \mathrm{~b}$ (Oikawa et al., 2013). According to those monitoring results, ${ }^{137} \mathrm{Cs}$ activities in surface waters for the five years before the accident (2006-2010) had apparently reached a nearly constant level of $1.6 \pm 0.26 \mathrm{mBq} \mathrm{L}^{-1}$, with the range of 1.1$2.2 \mathrm{mBqL}^{-1}$. In this study, the highest ${ }^{137} \mathrm{Cs}$ activity during the first cruise (KH11-E01) was $26 \mathrm{~Bq} \mathrm{~L}^{-1}$ at Stn. $1-3$ on 24 March and 16250 times higher than the average value of the last five years prior to the accident. The observed ${ }^{137} \mathrm{Cs}$ activity was a maximum $\left(186 \mathrm{~Bq} \mathrm{~L}^{-1}\right)$ in surface waters $(\leq 5 \mathrm{~m}$ depth) at Stn. 1-4 on 15 April 2011 and then declined exponentially (Fig. 3).
The ${ }^{134} \mathrm{Cs} /{ }^{137} \mathrm{Cs}$ activity ratio in the waters after the direct discharge (26 March 2011, Tsumune et al., 2012) was apparently constant at 1.03 (Table 1 in the supplement), and a higher value than that $(0.5)$ in the Chernobyl fallout (UNSCEAR, 2000). This ratio is consistent with that of $0.99 \pm 0.03$ in water samples collected at the north and south discharge channels of the FDNPP in March and April 2011 (Buesseler et al., 2011) and that of nearly 1 in the western North Pacific in April and May 2011 (Honda et al., 2012).

During three cruises, KH11-E01 (28/3-9/4), KR11-E02 (11/4-21/4), and YK11-E02 (25/4-7/5), both the intermediate and the bottom water samples were additionally collected to clarify the vertical dispersion or advection of the radionuclides. The ${ }^{131} \mathrm{I},{ }^{134} \mathrm{Cs}$, and ${ }^{137} \mathrm{Cs}$ activities and its activity ratios in the intermediate and bottom water samples are listed in Table 3. As expected, we detected ${ }^{131} \mathrm{I},{ }^{134} \mathrm{Cs}$, and ${ }^{137} \mathrm{Cs}$ in the intermediate and bottom waters in addition to surface waters during the MR11-E01 cruise (28/3-9/4). The ${ }^{131} \mathrm{I} /{ }^{137} \mathrm{Cs}$ ratios widely ranged in intermediate and bottom waters (Table 2). This wide variation might also reflect variability in sources of atmospheric dust and direct discharge as shown in the previous paragraph. About one month after direct release of contaminated wastewaters from the FDNPP reactors (on 26 March 2011: Tsumune et al., 2012), activities of ${ }^{137} \mathrm{Cs}$ in subsurface waters ( $>5 \mathrm{~m}$ depth) near the FDNPP $(30 \mathrm{~km}$ distance) were clearly higher than the background activities in coastal seawater of the western North Pacific prior to the accident (Inomata et al., 2009; MEXT, 2010; Oikawa et al., 2011).

\subsection{Spatial and temporal distributions of radiocesium in seawater (Phase 2)}

At the stations located far from the FDNPP (e.g., Stns. A1, B1, G1, I1, see Fig. 1c), ${ }^{137}$ Cs activities were high in subsurface waters (i.e., intermediate and bottom waters) in May 2011 (cruises 11WM01 and 11WM02: see Table 1 in the supplement) in Phase 2. Even at Stns. 2 to 26 located 100$300 \mathrm{~km}$ away from FDNPP, the respective activities of ${ }^{134} \mathrm{Cs}$ and ${ }^{137} \mathrm{Cs}$ ranged between $0.2 \mathrm{mBq} \mathrm{L}^{-1}$ and $60 \mathrm{mBq} \mathrm{L}^{-1}$ and between $1.4 \mathrm{mBq} \mathrm{L}^{-1}$ and $72 \mathrm{mBq} \mathrm{L}^{-1}$ in the subsurface waters (100-200 m depth) in August 2011 (cruise KY11-E03, Table 1 in the supplement). Similar results were observed in November (cruise KR11-E07). These results indicate that the FDNPP-derived radiocesium (that is, both ${ }^{134} \mathrm{Cs}$ and ${ }^{137} \mathrm{Cs}$ ) was transported over $300 \mathrm{~km}$ horizontally and $200 \mathrm{~m}$ in depth vertically.

To better understand the distribution of radiocesium throughout the water column in the monitored area, in the following section we use data obtained for ten cruises (11WM01 (9-14 May 2011) to 11WM14 (4-21 February 2012), Table 1 in the supplement) to discuss spatial and temporal variations of radiocesium in the coastal ocean. 
Table 2. Hydrographic parameters, activities, and activity ratios of ${ }^{131} \mathrm{I},{ }^{134} \mathrm{Cs}$, and ${ }^{137} \mathrm{Cs}$ in the surface waters during four cruises (i.e., KH11-E01, MR11-E01, KR11-E02, and YK11-E02).

\begin{tabular}{|c|c|c|c|c|c|c|c|c|c|c|c|c|c|c|c|c|c|c|c|c|}
\hline \multirow{3}{*}{$\begin{array}{l}\text { Station } \\
1-1\end{array}$} & \multirow{3}{*}{$\begin{array}{c}\text { Cruise } \\
\text { KH11-E01 }\end{array}$} & \multirow{3}{*}{$\begin{array}{r}\text { Sampling } \\
\text { date (JST) } \\
\text { 23-Mar-11 }\end{array}$} & Depth & Temp. & Salinity & & & & Acti & & $-1)$ & & & & & & Activit & y ratio & & \\
\hline & & & $(\mathrm{m})$ & $\left({ }^{\circ} \mathrm{C}\right)$ & & & ${ }^{131} \mathrm{I}$ & & & ${ }^{34} \mathrm{Cs}^{*}$ & & & ${ }^{7} \mathrm{Cs}^{*}$ & & & 37 & & ${ }^{134} \mathrm{C}$ & 13 & \\
\hline & & & & 7.5 & 33.7 & 24.9 & \pm & 0.6 & 14.1 & \pm & 0.5 & 16.4 & \pm & 0.6 & 1.5 & \pm & 0.1 & 0.86 & \pm & 0.04 \\
\hline & KH11-E01 & 24-Mar-11 & 1 & 7.4 & 33.7 & 22.3 & \pm & 0.6 & 12.9 & \pm & 0.5 & 15.1 & \pm & 0.6 & 1.5 & \pm & 0.1 & 0.85 & \pm & 0.05 \\
\hline & KH11-E01 & 25-Mar-11 & 1 & 7.7 & 33.8 & 3.5 & \pm & 0.3 & & - & & & - & & & & & & & \\
\hline & KH11-E01 & 26-Mar-11 & 1 & 7.8 & 33.8 & 18.1 & \pm & 6.1 & 12.2 & \pm & 4.4 & 16.4 & \pm & 5.1 & 1.1 & \pm & 0.5 & 0.74 & \pm & 0.36 \\
\hline & MR11-E01 & 01-Apr-11 & 4 & 7.9 & 33.7 & 11.0 & \pm & 3.9 & 2.0 & \pm & 3.6 & 4.1 & \pm & 3.8 & 2.7 & \pm & 2.7 & 0.48 & \pm & 0.99 \\
\hline $1-2$ & KH11-E01 & 23-Mar-11 & 1 & 7.9 & 33.7 & 30.0 & \pm & 0.8 & 11.2 & \pm & 0.6 & 11.2 & \pm & 0.6 & 2.7 & \pm & 0.2 & 1.0 & \pm & 0.1 \\
\hline & KH11-E01 & 24-Mar-11 & 1 & 7.5 & 33.7 & 16.9 & \pm & 0.6 & 7.7 & \pm & 0.5 & 8.3 & \pm & 0.6 & 2.0 & \pm & 0.2 & 0.93 & \pm & 0.09 \\
\hline & KH11-E01 & 25-Mar-11 & 1 & 7.7 & 33.8 & 3.3 & \pm & 0.3 & 0.7 & \pm & 0.18 & 0.7 & \pm & 0.2 & 4.7 & \pm & 1.2 & 1.1 & \pm & 0.4 \\
\hline & KH11-E01 & 27-Mar-11 & 1 & 7.3 & 33.7 & 5.4 & \pm & 0.3 & 1.3 & \pm & 0.2 & 1.5 & \pm & 0.2 & 3.6 & \pm & 0.5 & 0.87 & \pm & 0.19 \\
\hline & MR11-E01 & 30-Mar-11 & 4 & 7.8 & 33.7 & 3.3 & \pm & 4.4 & & - & & & - & & & & & & & \\
\hline & MR11-E01 & 03-Apr-11 & 4 & 7.3 & 33.7 & 6.0 & \pm & 3.7 & & - & & & - & & & & & & & \\
\hline $1-3$ & KH11-E01 & 23-Mar-11 & 1 & 7.9 & 33.8 & 76.8 & \pm & 1.4 & 21.4 & \pm & 0.9 & 24.1 & \pm & 1.0 & 3.2 & \pm & 0.1 & 0.89 & \pm & 0.05 \\
\hline & KH11-E01 & 24-Mar-11 & 1 & 7.7 & 33.8 & 57.4 & \pm & 0.9 & 22.7 & \pm & 0.7 & 26.1 & \pm & 0.7 & 2.2 & \pm & 0.1 & 0.87 & \pm & 0.04 \\
\hline & KH11-E01 & 25-Mar-11 & 1 & 7.7 & 33.8 & 29.0 & \pm & 0.8 & 8.7 & \pm & 0.5 & 8.0 & \pm & 0.5 & 3.6 & \pm & 0.2 & 1.1 & \pm & 0.1 \\
\hline & KH11-E01 & 26-Mar-11 & 1 & 8.1 & 33.7 & 15.3 & \pm & 6.0 & 1.8 & \pm & 3.5 & & - & & & & & & & \\
\hline & MR11-E01 & 01-Apr-11 & 4 & 7.7 & 33.7 & 2.0 & \pm & 3.6 & 3.2 & \pm & 3.4 & & - & & & & & & & \\
\hline & MR11-E01 & 09-Apr-11 & 4 & 8.5 & & 77.4 & \pm & 4.9 & 47.6 & \pm & 4.7 & 44.2 & \pm & 4.8 & 1.8 & \pm & 2 & 1.1 & \pm & 0.2 \\
\hline $1-4$ & KH11-E01 & 23-Mar-11 & 1 & 7.7 & 33.8 & 37.3 & \pm & 0.7 & 16.2 & \pm & 0.6 & 18.2 & \pm & 0.6 & 2.0 & \pm & .1 & 0.89 & \pm & 0.04 \\
\hline & KH11-E01 & 24-Mar-11 & 1 & 7.8 & 33.7 & 59.1 & \pm & 1.0 & 15.2 & \pm & 0.6 & 16.0 & \pm & 0.7 & 3.7 & \pm & .2 & .95 & \pm & 0.05 \\
\hline & KH11-E01 & 25-Mar-11 & 1 & 7.7 & 33.7 & 30.0 & \pm & 0.7 & 5.4 & \pm & 0.4 & 5.9 & \pm & 0.4 & 5.1 & \pm & 0.4 & 0.92 & \pm & 0.09 \\
\hline & KH11-E01 & 27-Mar-11 & 1 & 7.6 & 33.7 & 12.0 & \pm & 0.5 & 3.6 & \pm & 0.3 & 3.9 & \pm & 0.3 & 3.1 & \pm & 0.3 & 0.92 & \pm & 0.12 \\
\hline & MR11-E01 & 03-Apr-11 & 4 & 8.0 & 33.7 & 11.6 & \pm & 3.9 & & - & & & - & & & & & & & \\
\hline & KR11-E02 & 11-Apr-11 & 5 & 9.0 & 33.5 & 88.5 & \pm & 5.1 & 66.5 & \pm & 5.2 & 71.0 & \pm & 5.7 & 1.2 & \pm & 0.1 & 0.94 & \pm & 0.11 \\
\hline & KR11-E02 & 15-Apr-11 & 4 & 9.2 & 33 & 161 & \pm & 6.6 & 172 & \pm & 8 & 186 & \pm & 8. & 0.87 & \pm & 0.05 & 0.92 & \pm & 0.06 \\
\hline $2-1$ & KH11-E01 & 23-Mar-11 & 1 & 7.8 & 33.7 & 54.7 & \pm & 1.0 & 12.7 & \pm & 0.6 & 12.7 & \pm & 0.6 & 4.3 & \pm & 0.2 & 1.0 & \pm & 0.1 \\
\hline & KH11-E01 & 24-Mar-11 & 1 & 7.9 & & 40.5 & \pm & 0.9 & 11.6 & \pm & 0.6 & 11.1 & \pm & 0 & 6 & \pm & 2 & 1.0 & \pm & 0.1 \\
\hline & KH11-E01 & 25-Mar-11 & 1 & 7.8 & 3. & 25.0 & \pm & 0.7 & 2.8 & \pm & 0.3 & 3.1 & \pm & 0.3 & 8.1 & \pm & 8 & 0.90 & \pm & 0.13 \\
\hline & KH11-E01 & 26-Mar-11 & 1 & 8.2 & 33.7 & 14.0 & \pm & 5.9 & 16.5 & \pm & 4.4 & 5.9 & \pm & 4.5 & 2.4 & \pm & 2.1 & 2.8 & \pm & 2.2 \\
\hline & MR11-E01 & 28-Mar-11 & 4 & 7.9 & 33.7 & 7.0 & \pm & 5.0 & 11.8 & \pm & 4.1 & 19.6 & \pm & 5.0 & 0.36 & \pm & 0.27 & 0.60 & \pm & 0.26 \\
\hline & MR11-E01 & 01-Apr-11 & 4 & 8.2 & 33. & 12.0 & \pm & 4.1 & 10.2 & \pm & 4.0 & 15.7 & \pm & 4.4 & 0.76 & \pm & 0.34 & 0.65 & \pm & 0.31 \\
\hline & MR11-E01 & 05-Apr-11 & 3 & 8.3 & 33. & 49.7 & \pm & 4.4 & 41.5 & \pm & 4.2 & 37.5 & \pm & 4.5 & 1.3 & \pm & 0.2 & 1.1 & \pm & 0.2 \\
\hline & MR11-E01 & 09-Apr-11 & 5 & 7.9 & 33. & 8.6 & \pm & 2.6 & & - & & & - & & & & & & & \\
\hline & KR11-E02 & 13-Apr-11 & 4 & 8.9 & 33 & 64.1 & \pm & 4.4 & 48.0 & \pm & 4.9 & 54.3 & \pm & 5.2 & 1.2 & \pm & 0.1 & 0.88 & \pm & 0.12 \\
\hline & KR11-E02 & 17-Apr-11 & 4 & 9.3 & 336 & 68.4 & \pm & 4.2 & 88.0 & \pm & 5.9 & 83.3 & \pm & 6.1 & 0.82 & \pm & 0.08 & 1.1 & \pm & 0.1 \\
\hline $2-2$ & KH11-E01 & 23-Mar-11 & 1 & 7.6 & & 42.0 & \pm & 0.9 & 11.5 & \pm & 0.6 & 12.8 & \pm & 0. & 3.3 & \pm & .2 & 0.90 & \pm & 0.06 \\
\hline & KH11-E01 & 24-Mar-11 & 1 & 8.0 & & 36.2 & \pm & 0.7 & 16.3 & \pm & 0.6 & 16.9 & \pm & 0. & 2.1 & \pm & 1 & 0.96 & \pm & 0.05 \\
\hline & KH11-E01 & 25-Mar-11 & 1 & 8.0 & 3 & 18.0 & \pm & 0.6 & 2.0 & \pm & 0.3 & 2.6 & \pm & 0 & 9 & \pm & .7 & 0.77 & \pm & 0.13 \\
\hline & KH11-E01 & 27-Mar-11 & 1 & 7.7 & 33 & 15.0 & \pm & 0.5 & 2.8 & \pm & 0.3 & 2.3 & \pm & 0 & 6.5 & \pm & 8.8 & 1.2 & \pm & 0.2 \\
\hline & MR11-E01 & 30-Mar-11 & 3 & 8.5 & & 8.7 & \pm & 4.7 & 15.8 & \pm & 3.2 & 5 & \pm & 4 & 1.0 & \pm & 8.8 & 1.9 & \pm & 1.1 \\
\hline & MR11-E01 & 03-Apr-11 & 4 & 8.1 & 33. & 18.3 & \pm & 4.2 & 7.3 & \pm & 4.3 & 10.7 & \pm & 4.6 & 1.7 & \pm & 0.8 & 0.68 & \pm & 0.50 \\
\hline & MR11-E01 & 07-Apr-11 & 5 & 8.4 & 33 & 56.3 & \pm & 4.3 & 36.5 & \pm & 3.5 & 19.8 & \pm & 3.7 & 2.8 & \pm & 0.6 & 1.8 & \pm & 0.4 \\
\hline & KR11-E02 & $r-11$ & 4 & 8.4 & & 13.9 & \pm & 3.0 & & - & & & - & & & & & & & \\
\hline & KR11-I & 1 & 1 & 9.2 & & 36.6 & \pm & 3.6 & 41.9 & \pm & 4. & 39.5 & \pm & 4. & .93 & \pm & 0.14 & 1.1 & \pm & 0.2 \\
\hline & KR11-E & 19-Apr-11 & ( & 89 & & 18.8 & \pm & 2.9 & 27.8 & \pm & 3.9 & 316 & \pm & 4 & 99 & \pm & 0.12 & 0.88 & \pm & 0.17 \\
\hline $2-3$ & KH11-E01 & 23-Mar-11 & 1 & 7.2 & & 29.0 & \pm & 0.8 & 14.7 & \pm & 0.7 & 15.3 & \pm & 0. & 1.9 & \pm & 0.1 & 0.96 & \pm & 0.06 \\
\hline & KH11-E01 & 24-Mar-11 & 1 & 7.9 & & 33.4 & \pm & 0.8 & 12.1 & \pm & 0.5 & 12.2 & \pm & 0 & 2.7 & \pm & .1 & 0.99 & \pm & 0.07 \\
\hline & KH11-E01 & 25-Mar-11 & 1 & 8.8 & 33 & 13.0 & \pm & 0.5 & 1.7 & \pm & 0.3 & 1.7 & \pm & 0 & 7.6 & \pm & 1.1 & 1.0 & \pm & 0.2 \\
\hline & KH11-E01 & 26-Mar-11 & 1 & 8.2 & & 6.6 & \pm & 5.7 & 8.2 & \pm & 3.6 & 2.8 & \pm & 4. & 2.3 & \pm & 4.0 & 2.9 & \pm & 4.5 \\
\hline & MR11-E01 & 28-Mar-11 & 4 & 8.2 & & 5 & \pm & 4.9 & 1.8 & \pm & 3.4 & 3.5 & \pm & 4.1 & 1.6 & \pm & 2.4 & 0.53 & \pm & 1.17 \\
\hline & MR11-E01 & $r-11$ & 4 & 8.6 & & 8. & \pm & 4.0 & 3.8 & \pm & 3.5 & 11.7 & \pm & 4.1 & 0.70 & \pm & 0.42 & 0.32 & \pm & 0.32 \\
\hline & M & 09-Apr- & 5 & 8 & & 14. & \pm & 3.0 & & - & & & - & & & & & & & \\
\hline & KR11-E02 & 17-Apr-11 & 4 & 9.6 & & 49.0 & \pm & 3.6 & 52.1 & \pm & 4.8 & 53.3 & \pm & 5 . & 0.92 & \pm & 0.11 & 0.98 & \pm & 0.13 \\
\hline $2-4$ & KH11-E01 & 23-Mar-1 & 1 & 7.3 & & 39.4 & \pm & 0.8 & 15.1 & \pm & 0.6 & 15 & \pm & 0. & 2.6 & \pm & 0.1 & 0.99 & \pm & 0.06 \\
\hline & KH11-E01 & 24-Mar-11 & 1 & 7.9 & & 37.5 & \pm & 0.8 & 13.3 & \pm & 0.6 & 13.4 & \pm & 0 & 2.8 & \pm & .1 & .99 & \pm & 0.07 \\
\hline & KH11-E01 & 25-Mar-11 & 1 & 7.8 & & 12.0 & \pm & 0.5 & 2.0 & \pm & 0.3 & 2.7 & \pm & 0 & 4.4 & \pm & 0.5 & 0.74 & \pm & 0.12 \\
\hline & KH11-E01 & 27-Mar-11 & 1 & 8.4 & & 8.5 & \pm & 0.4 & 1.2 & \pm & 0.2 & 1.6 & \pm & 0.2 & 5.3 & \pm & 0.8 & 0.75 & \pm & 0.17 \\
\hline & 11-E01 & 30-Mar-11 & $\sigma_{-1}$ & 8. & & 2 & \pm & 4.4 & & - & & & - & & & & & & & \\
\hline & MR11-E01 & 03-Apr-11 & 4 & 8. & & 5 & \pm & 3.4 & 3.9 & \pm & 4.2 & 1.2 & \pm & 4.0 & 4.8 & \pm & 17 & 3.4 & \pm & 12 \\
\hline & MR11-E01 & 07-Apr-11 & 4 & 8.4 & 33. & 10.1 & \pm & 2.9 & 7.9 & \pm & 1.9 & 9.9 & \pm & 3.0 & 1.0 & \pm & 0.4 & 0.80 & \pm & 0.31 \\
\hline & KR11-E & & 列 & & & & \pm & 3.0 & & - & & & - & & & & & & & \\
\hline & KR11-E02 & 15-Apr-11 & 4 & 9.5 & 3 & 34.4 & \pm & 3.6 & 34.6 & \pm & 4.1 & 33.3 & \pm & 4. & 1.0 & \pm & 0.2 & 1.0 & \pm & 0.2 \\
\hline & KR11-E0 & 29-Apr-11 & 3 & 9.7 & & 14.7 & \pm & 2.3 & 58.0 & \pm & 4.4 & 53.0 & \pm & 5 & 0.28 & \pm & 0.05 & 1.1 & \pm & 0.1 \\
\hline $2-5$ & MR11-E01 & 28-Mar-11 & 3 & 9.0 & 33.9 & 11.8 & \pm & 0.7 & 3.8 & \pm & 0.5 & 4.1 & \pm & 0. & 2.9 & \pm & 0.4 & 0.91 & \pm & 0.18 \\
\hline & MR11-E01 & 01-Apr-11 & 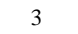 & 11.3 & 34.2 & 7.8 & \pm & 0.6 & & - & & 2.0 & \pm & 0. & 3.8 & \pm & 1.1 & & & \\
\hline & KR11-E02 & 17-Apr-11 & 4 & 11 & & 36.6 & \pm & 3.2 & 38.6 & \pm & 4.5 & 38.5 & \pm & 4. & 0.95 & \pm & 0.14 & 1.0 & \pm & 0.2 \\
\hline $2-6$ & MR11-E01 & 30-Mar-11 & 4 & 7.7 & 33.5 & 79.4 & \pm & 1.0 & 6.5 & \pm & 0.6 & 7.2 & \pm & 0.6 & 11 & \pm & 0.9 & 0.89 & \pm & 0.11 \\
\hline & 111-E01 & 03-Apr-11 & 4 & 9.4 & 33 & 37.5 & \pm & 0.7 & 5.0 & \pm & 0.5 & 4.8 & \pm & 0.6 & 7.9 & \pm & 1.0 & 1.1 & \pm & 0.2 \\
\hline & MR11-E01 & 07-Apr-11 & 4 & 9.3 & 33.8 & 25.1 & \pm & 3.5 & 8.8 & \pm & 2.2 & & - & & & & & & & \\
\hline & YK11-E02 & 25-Apr-11 & 5 & 11.5 & 33.8 & 21.5 & \pm & 2.7 & 38.6 & \pm & 4.3 & 40.0 & \pm & 4.6 & 0.54 & \pm & 0.09 & 0.97 & \pm & 0.16 \\
\hline
\end{tabular}

* “-": Activity of the samples was calculated for all the samples as long as total counts were greater than the background without setting any detection limit. Samples for direct measurement by gamma-ray spectrometry were 0.5 or $2 \mathrm{~L}$ aliquots of the water samples in order to provide only radiocesium values. Data on ${ }^{134} \mathrm{Cs}$ and ${ }^{137} \mathrm{Cs}$ at sampling stations where radioiodine was not detected were excluded in this table. See Table 1 in the Supplement for all the data on radiocesium. 

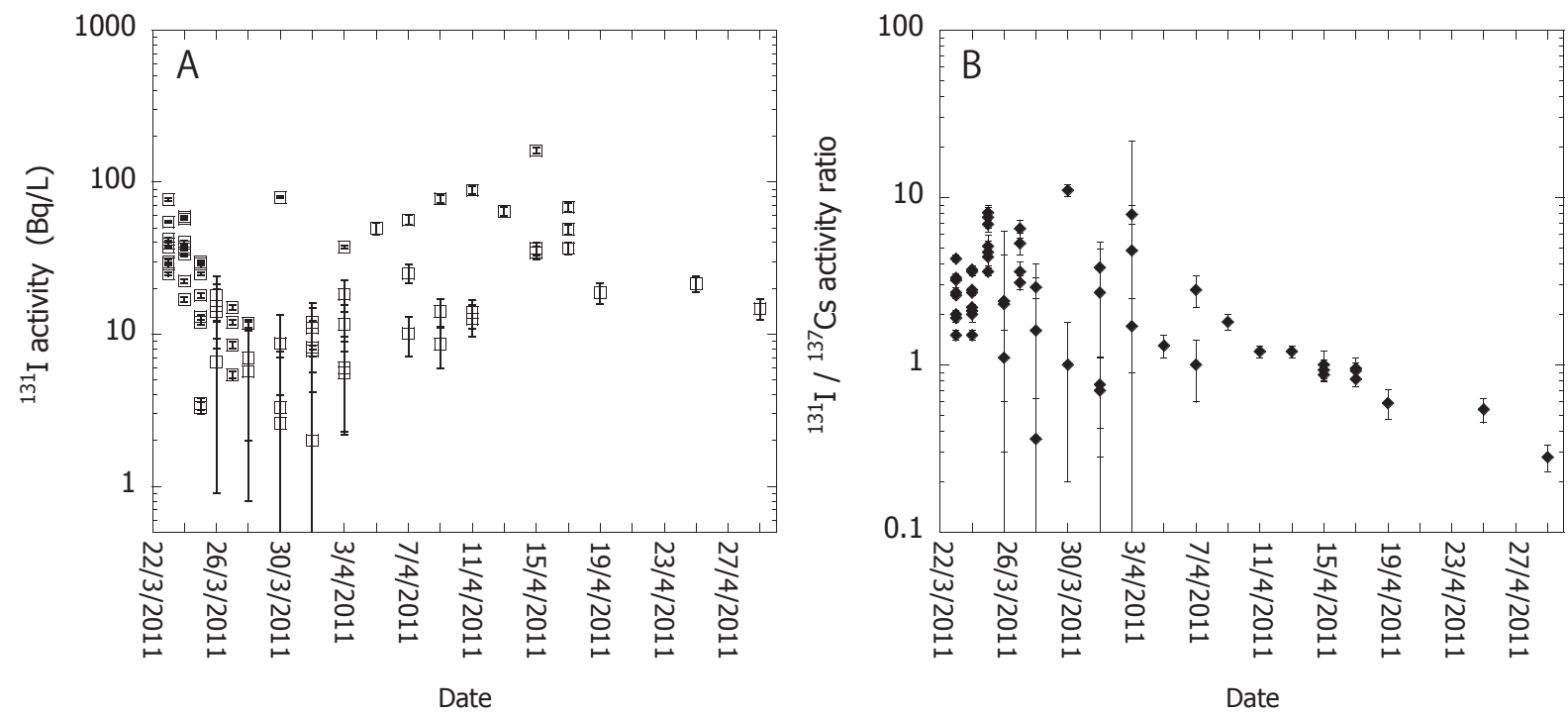

Fig. 2. Temporal variation of ${ }^{131} \mathrm{I}$ activities in surface waters $(\mathbf{A})$ and ${ }^{131} \mathrm{I} /{ }^{137} \mathrm{Cs}$ activity ratios in surface waters (B).

\subsubsection{Temporal variation of radiocesium in surface seawaters}

Figure 4 shows the temporal variation in the distributions of temperature, salinity, and ${ }^{137} \mathrm{Cs}$ activities in surface waters from 9-14 May 2011 to 4-21 February 2012. During 9-14 May, high ${ }^{137} \mathrm{Cs}$ activities $\left(\sim 1.0 \mathrm{BqL}^{-1}\right)$ were observed in northern and northeastern areas (from Stns. B1-3 to E1-3; see Fig. 1c). In contrast, the ${ }^{137} \mathrm{Cs}$ activities at stations located to the southeast of the FDNPP were relatively low, specifically, 0.14, 0.035, and $0.61 \mathrm{BqL}^{-1}$ at Stns. F1, G2, and $\mathrm{H} 1$, respectively. However, the ${ }^{137} \mathrm{Cs}$ activity at Stn. G1 was high $\left(5.4 \mathrm{BqL}^{-1}\right)$. The relatively high activities in the northeastern area can be ascribed to a pattern of coastal currents. Based on a model simulation, Tsumune et al. (2012) reported that a water mass with high ${ }^{137} \mathrm{Cs}$ activity was transported southward along the coast by the coastal current until April, and then that water mass was advected northward during May.

At Stns. I1-3 to L1-4 located in the southernmost area of this study (Fig. 1c), ${ }^{137} \mathrm{Cs}$ activities during 9-14 May 2011 ranged between $2.5 \mathrm{mBqL}^{-1}$ and $0.11 \mathrm{BqL}^{-1}$ or even less than the limit of detection (Fig. 4). The low ${ }^{137} \mathrm{Cs}$ activities probably resulted from a cyclonic mesoscale eddy (Aoyama et al., 2012), which was present by the end of May (Kawamura et al., 2011; Tsumune et al., 2012). The presence of the eddy was also evidenced by high temperatures $\left(\sim 20^{\circ} \mathrm{C}\right)$ and high salinities $(>34)$ in the corresponding area. The eddy disappeared during the period 6-10 June. Simultaneously, ${ }^{137} \mathrm{Cs}$ activity at Stns. J1-J3 to L1-L2 increased. In particular, relatively high activities $\left(1.0-4.6 \mathrm{~Bq} \mathrm{~L}^{-1}\right)$ were observed at Stns. I1, J1, K1, and L1 near the coastline.

The ${ }^{137} \mathrm{Cs}$ activities in the surface waters at the northernmost stations (A1, A2 and A3) were generally lower than

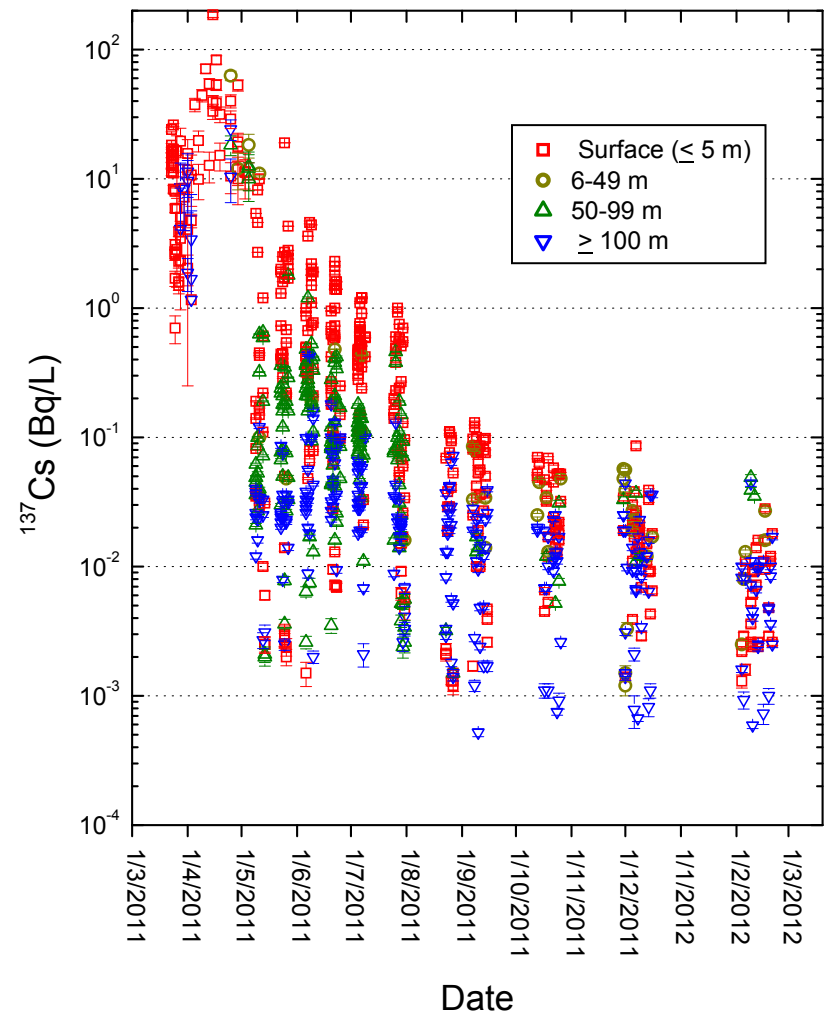

Fig. 3. Temporal variation of ${ }^{137} \mathrm{Cs}$ activities in coastal waters off Miyagi, Fukushima, and Ibaraki from 23 March 2011 to 21 February 2012 .

those of Stns. B1 to B4 (Fig. 1). However, the ${ }^{137}$ Cs activities were lower from 9-14 May to 6-10 June than in surface waters at Stns. B1 to B4, which are closer to the FDNPP. The water mass salinity around Stns. A1, A2 and A3 was different 
Table 3. Hydrographic parameters, activities, and activity ratios of ${ }^{131} \mathrm{I},{ }^{134} \mathrm{Cs}$, and ${ }^{137} \mathrm{Cs}$ in the water below the surface layer $(\leq 5 \mathrm{~m})$.

\begin{tabular}{|c|c|c|c|c|c|c|c|c|c|c|c|c|c|c|c|c|c|c|c|c|}
\hline \multirow{3}{*}{$\begin{array}{l}\text { Sampling } \\
\text { station } \\
1-1\end{array}$} & \multirow{3}{*}{$\begin{array}{c}\text { Cruise } \\
\text { MR11-E01 }\end{array}$} & \multirow{3}{*}{$\begin{array}{c}\begin{array}{c}\text { Sampling date } \\
\text { (JST) }\end{array} \\
\text { 01-Apr-11 }\end{array}$} & \multirow{3}{*}{$\begin{array}{c}\begin{array}{c}\text { Depth } \\
(\mathrm{m})\end{array} \\
114\end{array}$} & \multirow{3}{*}{$\begin{array}{c}\text { Temp } \\
\left({ }^{\circ} \mathrm{C}\right) \\
6.7\end{array}$} & \multirow{3}{*}{$\begin{array}{c}\text { Salinity } \\
33.67\end{array}$} & \multicolumn{9}{|c|}{ Activity $\left(\mathrm{BqL}^{-1}\right)$} & \multicolumn{6}{|c|}{ Activity ratio } \\
\hline & & & & & & \multicolumn{3}{|c|}{${ }^{131} \mathrm{I}$} & \multicolumn{3}{|c|}{${ }^{134} \mathrm{Cs}^{*}$} & \multicolumn{3}{|c|}{${ }^{137} \mathrm{Cs}^{*}$} & \multicolumn{3}{|c|}{${ }^{131} \mathrm{I} /{ }^{137} \mathrm{Cs}$} & \multicolumn{3}{|c|}{${ }^{134} \mathrm{Cs} /{ }^{137} \mathrm{Cs}$} \\
\hline & & & & & & 2.6 & \pm & 3.5 & 8.5 & \pm & 3.8 & & - & & & & & & & \\
\hline $1-2$ & MR11-E01 & 30-Mar-11 & 121 & 6.5 & 33.64 & 0.44 & \pm & 4.4 & & - & & & - & & & & & & & \\
\hline $1-2$ & MR11-E01 & 03-Apr-11 & 120 & 6.1 & 33.61 & 1.6 & \pm & 3.3 & & - & & & - & & & & & & & \\
\hline $1-3$ & MR11-E01 & 28-Mar-11 & 122 & 6.6 & 33.65 & 0.65 & \pm & 4.7 & 4.2 & \pm & 3.6 & & - & & & & & & & \\
\hline $1-3$ & MR11-E01 & 01-Apr-11 & 120 & 6.2 & 33.62 & 4.3 & \pm & 3.6 & 11 & \pm & 4 & 9.7 & \pm & 4.2 & 0.44 & \pm & 0.42 & 1.2 & \pm & 0.7 \\
\hline $1-4$ & MR11-E01 & 30-Mar-11 & 127 & 6.0 & 33.62 & 2.0 & \pm & 4.3 & & - & & & - & & & & & & & \\
\hline $1-4$ & MR11-E01 & 03-Apr-11 & 127 & 6.5 & 33.65 & 3.0 & \pm & 3.5 & 0.48 & \pm & 3.8 & 1.2 & \pm & 4.0 & 2.6 & \pm & 9.3 & 0.41 & \pm & 3.53 \\
\hline $2-1$ & MR11-E01 & 28-Mar-11 & 137 & 7.4 & 33.70 & 2.2 & \pm & 4.7 & 3.8 & \pm & 3.7 & 8.6 & \pm & 4.6 & 0.25 & \pm & 0.56 & 0.44 & \pm & 0.48 \\
\hline $2-2$ & MR11-E01 & 30-Mar-11 & 141 & 6.3 & 33.63 & 0.22 & \pm & 4.3 & 9.3 & \pm & 2.8 & & - & & & & & & & \\
\hline $2-4$ & MR11-E01 & 03-Apr-11 & 172 & 5.9 & 33.60 & 2.0 & \pm & 3.4 & 2.1 & \pm & 3.9 & 3.4 & \pm & 4.2 & 0.58 & \pm & 1.2 & 0.63 & \pm & 1.37 \\
\hline $2-5$ & MR11-E01 & 28-Mar-11 & 132 & 8.0 & 33.79 & 1.9 & \pm & 0.6 & & - & & & - & & & & & & & \\
\hline $2-5$ & MR11-E01 & $01-A p r-11$ & 133 & 8.0 & 33.78 & 4.8 & \pm & 0.5 & & - & & 1.9 & \pm & 0.5 & 2.6 & \pm & 0.8 & & & \\
\hline $2-6$ & MR11-E01 & 30-Mar-11 & 83 & 8.3 & 33.81 & 6.1 & \pm & 0.6 & 2.1 & \pm & 0.5 & & - & & & & & & & \\
\hline $2-6$ & YK11-E02 & 25 -Apr-11 & 49 & 9.6 & 33.77 & 22 & \pm & 3 & 53 & \pm & 5 & 63 & \pm & 5 & 0.36 & \pm & 0.05 & 0.85 & \pm & 0.10 \\
\hline
\end{tabular}

* “-”: Activity of the samples was calculated for all the samples as long as total counts were greater than the background without setting any detection limit. Samples for direct measurement by gamma-ray spectrometry were 0.5 or $2 \mathrm{~L}$ aliquots of the water samples in order to provide only radiocesium values. Data on ${ }^{134} \mathrm{Cs}$ and ${ }^{137} \mathrm{Cs}$ at sampling stations where radioiodine was not detected were excluded in this table. See Table 1 in the Supplement for all the data on radiocesium.
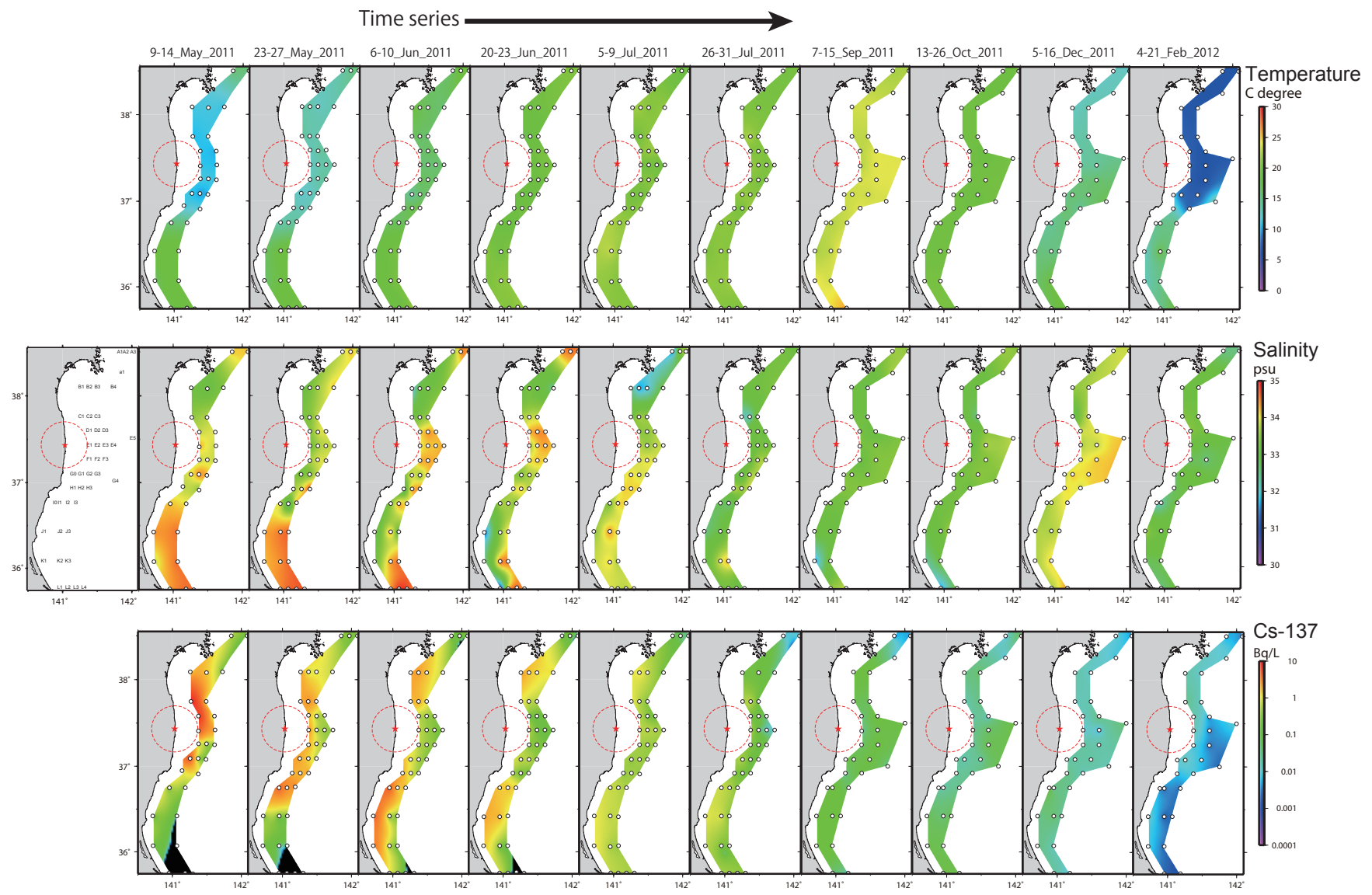

Fig. 4. Horizontal distributions of temperature (A), salinity (B), and ${ }^{137} \mathrm{Cs}$ activities $(\mathbf{C})$ in surface water and their temporal changes from 9-14 May 2011 to 4-21 February 2012.

from that around Stns. B1, B2, B3, and B4 (Fig. 4); the former stations had a value of $>34$ psu and the latter, $>33$ psu. This implied presence of a water mass with low ${ }^{137} \mathrm{Cs}$. The
${ }^{137} \mathrm{Cs}$ activities at all the stations gradually decreased from 6-10 June 2011 to 4-21 February 2012. 
3.2.2 Temporal variation in the distribution of radiocesium in intermediate and bottom waters

The activities of ${ }^{137} \mathrm{Cs}$ at depths $>5 \mathrm{~m}$ for all the stations ranged from $2.0 \mathrm{mBqL}^{-1}$ to $11 \mathrm{BqL}^{-1}$ with a geometric mean of $47 \mathrm{mBq} \mathrm{L}^{-1}$ during the period 4-14 May 2011. During the period 23-27 May 2011, these activities increased to $57 \mathrm{mBq} \mathrm{L}^{-1}$ and then reached a maximum of $95 \mathrm{mBq} \mathrm{L}^{-1}$ on $6-10$ June 2011 . These results suggested that waters containing the FDNPP-derived radiocesium were transported downward during the sampling periods.

To elucidate the downward transport of FDNPP-derived radiocesium, activities of ${ }^{134} \mathrm{Cs}$ at each depth were obtained and are shown in Fig. $5 ;{ }^{134} \mathrm{Cs}$ is an ideal tracer for the FDNPP accident because there was no ${ }^{134} \mathrm{Cs}$ background activity before 11 March due to its short-life. A plot of decaycorrected ${ }^{134} \mathrm{Cs}$ activities versus time (Fig. 5) reveals that at Stns. D1, E1, F1, and G1 (near the FDPP) ${ }^{134}$ Cs activities at a depth of $50 \mathrm{~m}$ increased by factors of 3-10 in about 1 month (from 9-14 May 2011 to 6-10 June 2011); the maxima were $0.39,0.22,0.37$, and $0.22 \mathrm{~Bq} \mathrm{~L}^{-1}$, respectively. Similar results were obtained even at Stns. D3, E3, F3, and G3, which were located about $100 \mathrm{~km}$ further from the coast than Stns. D1-G1. In addition, at a depth of $100 \mathrm{~m}$, the maximum activity was measured at $\mathrm{Stn}$. E3 $\left(52 \mathrm{mBq} \mathrm{L}^{-1}\right)$ on 7 June 2011 or about two weeks later at Stns. D3 $\left(74 \mathrm{mBq} \mathrm{L}^{-1}\right), \mathrm{F} 3$ $\left(0.17 \mathrm{BqL}^{-1}\right), \mathrm{G} 3\left(0.1 \mathrm{BqL}^{-1}\right)$, and $\mathrm{H} 3\left(0.1 \mathrm{BqL}^{-1}\right)$. The ranges of ${ }^{134} \mathrm{Cs}$ activities at 50 and $100 \mathrm{~m}$ at these stations were comparable to those in the surface waters during June 2011 (Fig. 5). From 7-15 September 2011 to 4-21 February 2012, the ranges of ${ }^{134} \mathrm{Cs}$ activities in the bottom waters were similar to the ranges in the surface waters at all the stations, with the exception of Stns. A3 and J3. No activities of ${ }^{134} \mathrm{Cs}$ in the bottom waters at these stations on 7-15 September 2011 were observed. The fact that ${ }^{134} \mathrm{Cs}$ was not detected in the bottom water samples of these two exceptional stations suggested that radiocesium derived from the FDNPP accident was not transported to such relatively great depths. Moreover, ${ }^{137} \mathrm{Cs}$ activities in the bottom waters (453-576 m depth) ranged between 0.78 and $1.7 \mathrm{mBq} \mathrm{L}^{-1}$ throughout the sampling periods. This implied that FDNPP-derived radiocesium was transported to depths as great as $\sim 200 \mathrm{~m}$ in coastal waters within six months after the FDNPP accident.

In general, sinking particles include biogenic and lithogenic materials. Zooplankton excretion is considered to account for the vertical transport of sinking biogenic particles; the production of fecal pellets acts as a biological pump (Honda et al., 2002). On the basis of sediment trap data and plankton collections, Fowler et al. (1987) previously reported that radioisotopes from the Chernobyl accident were removed from surface waters of the Mediterranean Sea by zooplankton grazing; the consumed radionuclides that had been packaged into the large fecal pellets sank rapidly.

In the coastal waters off Fukushima and Miyagi Prefectures, Kaeriyama et al. (2012) reported that ${ }^{137} \mathrm{Cs}$ ac- tivities in zooplankton at $50 \mathrm{~m}$ depth ranged from 0.88 to 29 Bq kg-wet weight ${ }^{-1}$ during June 2011 to February 2012, whereas ${ }^{137} \mathrm{Cs}$ activities in surrounding waters at the same depth were low $\left(10 \mathrm{mBqL}^{-1}\right.$ to $\left.0.9 \mathrm{BqL}^{-1}\right)$. They estimated the zooplankton-to-water activity ratio of ${ }^{137} \mathrm{Cs}$ to be $(3.3-$ $4.4) \times 10^{2} \mathrm{~L} \mathrm{~kg}^{-1}$ which is clearly higher than the reported concentration ratio of Cs for zooplankton $\left(40 \mathrm{~L} \mathrm{~kg}^{-1}\right)$ published by the IAEA (2004). However, the contribution of zooplankton to the downward flux of ${ }^{137} \mathrm{Cs}$ through the subsurface water column within a few months after the FDNPP accident is thought to be small because the biomass of zooplankton is not high. For example, Kaeriyama et al. (2008) showed that the integrated biomass of zooplankton in the depth interval $0-150 \mathrm{~m}$ in coastal waters off Aomori and Iwate Prefectures (to the northern neighbor of Miyagi Prefecture) ranged from 6.3 to $56.8 \mathrm{~g}$-wet weight $\mathrm{m}^{-2}$ in October 2005 and June 2006. By multiplying this biomass by the ${ }^{137} \mathrm{Cs}$ activities in the zooplankton, we roughly estimated the inventory of Fukushima-derived ${ }^{137} \mathrm{Cs}$ in the zooplankton to be $5.5 \mathrm{mBq} / \mathrm{m}^{2}$ to $1.6 \mathrm{~Bq} \mathrm{~m}^{-2}$ in the coastal areas. This range was considerably lower than the inventory of ${ }^{137} \mathrm{Cs}$ activity in coastal and open ocean waters $\left(6.2-16 \mathrm{kBq} \mathrm{m}^{-2}\right.$; Buesseler et al., 2012).

Clay minerals derived from lithogenic materials are also known to accumulate ${ }^{137}$ Cs (Comans et al., 1991; Sakuma and Kawamura, 2011). In ${ }^{137}$ Cs speciation experiments conducted by Otosaka and Kobayashi (2012), more than $75 \%$ of ${ }^{137} \mathrm{Cs}$ derived from the FDNPP accident in coastal sediments was adsorbed/incorporated onto/into irreversible fractions. Because we analyzed unfiltered seawater samples in this study, the samples would have included soluble, colloidal, and particulate fractions. The fraction of Cs associated with particles in water samples is expected to be small because Cs is not very particle-reactive (e.g., its distribution coefficient $\left.\left(K_{\mathrm{d}}\right)=4 \times 10^{3} \mathrm{~L} \mathrm{~kg}^{-1}\right)$ compared to other scavenging metals such as $\mathrm{Mn}, \mathrm{Fe}$, and Th $\left(K_{\mathrm{d}}: 2 \times 10^{6}\right.$ to $3 \times 10^{8} \mathrm{~L} \mathrm{~kg}^{-1}$; IAEA, 2004; Takata et al., 2010). Soluble forms are therefore expected to account for most of the radiocesium activity in seawater samples, indicating the loss of a relatively low amount of the activities in waters by sinking of the radiocesium in the particulate phase or the protection of radiocesium in the dissolved phase from scavenging because of its thermodynamically stable forms. It is thus unlikely that redistribution of radiocesium derived from the FDNPP accident in the water column onto particles had much to do with the rapid increase of the activity in seawater at depths of 5$200 \mathrm{~m}$.

As described in the Introduction, vertical water mixing can account for much of the downward flux of radiocesium. Diapycnal mixing in coastal areas is mainly a function of diurnal tidal currents, the result being a vertically homogeneous structure of physical characteristics (i.e., $\sigma_{t}$, salinity, and temperature) of the water. In addition, during the winter, strong cooling and wind forcing of the mixed layer induce convection cells that extend to depths ranging from one to a 


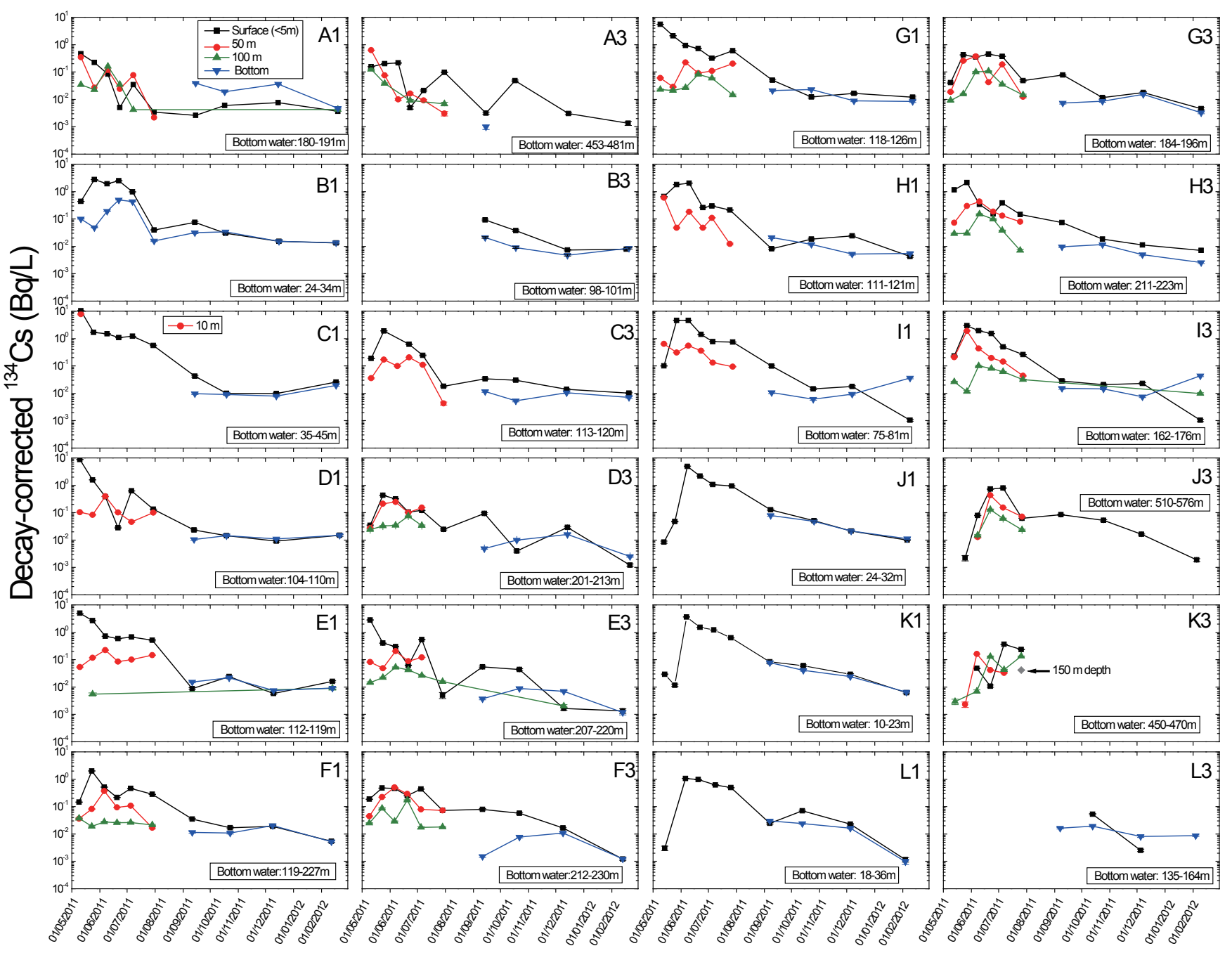

Fig. 5. Temporal variation of ${ }^{134} \mathrm{Cs}$ activities in seawater at each sampling depth. Error bars are less than or equal to the size of the symbols. Activities of ${ }^{134} \mathrm{Cs}$ were decay-corrected to $26 \mathrm{March} 2011$. Activities of ${ }^{134} \mathrm{Cs}$ in bottom waters were not detected at any stations from $9-14$ May to 26-31 July by direct measurement with a gamma-ray spectrometer.

few hundred meters. Figure 6 shows the temporal changes of $\sigma_{t}$ in the coastal waters from 9-14 May 2011 to 4-21 February 2012. The formation of a vertically homogeneous water mass during 4-21 February 2012 could be due to vigorous vertical mixing during the winter. This vertical mixing contributed to the downward flux of radiocesium into bottom waters, the result being nearly constant ${ }^{134} \mathrm{Cs}$ activities throughout the water column at each station during February 2012 (Fig. 5). However, ${ }^{134}$ Cs derived from the FDNPP accident was observed at depths of $\sim 200 \mathrm{~m}$ before the winter (Fig. 5). Although the formation of a vertically homogeneous water column during Phase 1 could be due to vertical mixing during the winter (Fig. 6), relatively high radiocesium activities (especially for ${ }^{134} \mathrm{Cs}$ ) were observed in subsurface waters during Phase 1, at only Stns. 2-6 (49 m depth) and S4 (61 m depth) on 25 April and Stn. 1-B (30 m depth) on 5 May 2011. However, radiocesium activities in subsurface waters, especially at water depths of more than $100 \mathrm{~m}$, were not detected. Thus, it is unclear that the radiocesium derived from the FDNPP accident was transported to bottom depth during the Phase 1 period. Indeed, processes other than diapycnal mixing during the winter could have affected the vertical flux of radiocesium in coastal waters during the period from 9-14 May to 5-16 December 2011.

Isopycnal mixing could contribute to the transport of radiocesium from surface waters to intermediate and bottom waters. For example, chemical constituents such as the soluble forms of nutrients are transported or supplied along isopycnal surfaces (Sasaki and Hiroe, 2002). From spring to autumn, diapycnal mixing attributed to the combined effects of coastal currents and diurnal tidal currents is thought to account for most vertical transport (Matsuura et al., 2007). In this study, the homogeneous water column was not observed at any station from 9-14 May to 5-16 December 2011 


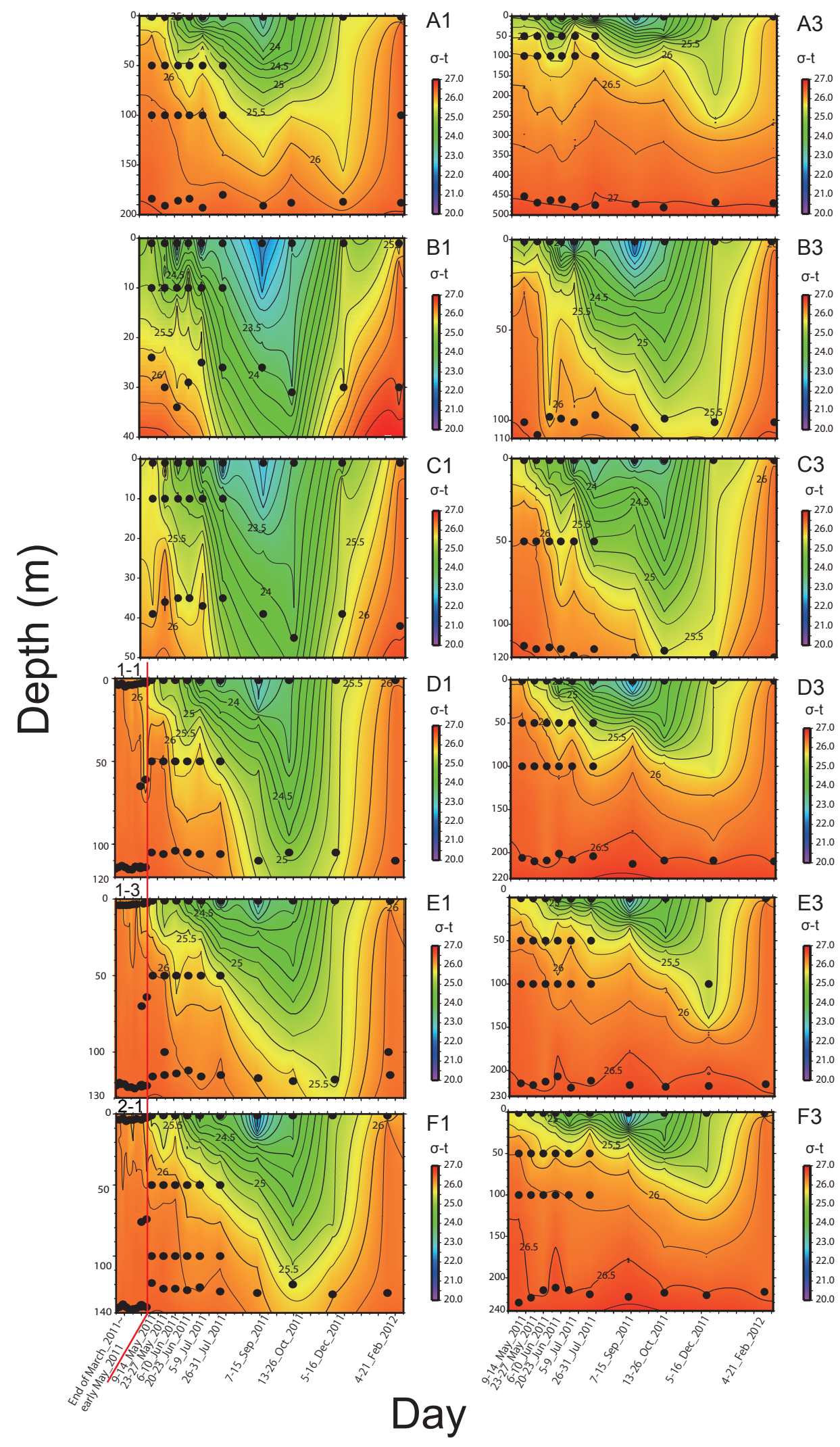

Fig. 6. Vertical distributions of $\sigma_{t}$ and their temporal changes. Solid circles indicate sampling depths. Data taken at Stns. 1-1, 1-3 and 2-1 in Phase 1, which were at almost the same locations as Stns. D-1, E-1 and F-1, respectively, were also plotted on the left side of the red line in the correspondent figures. 

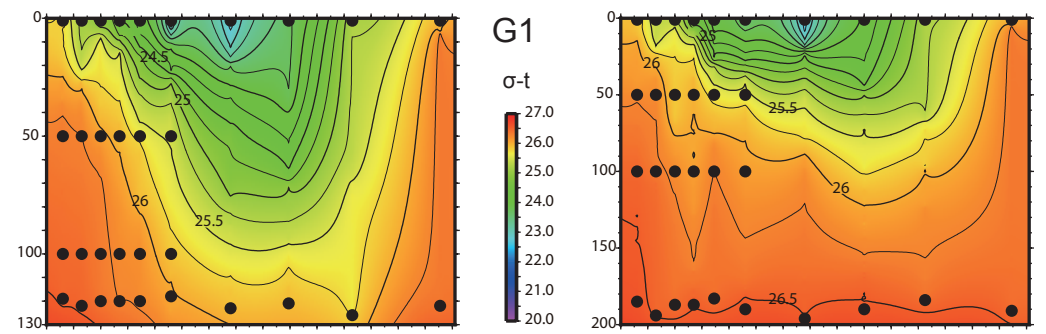

G3
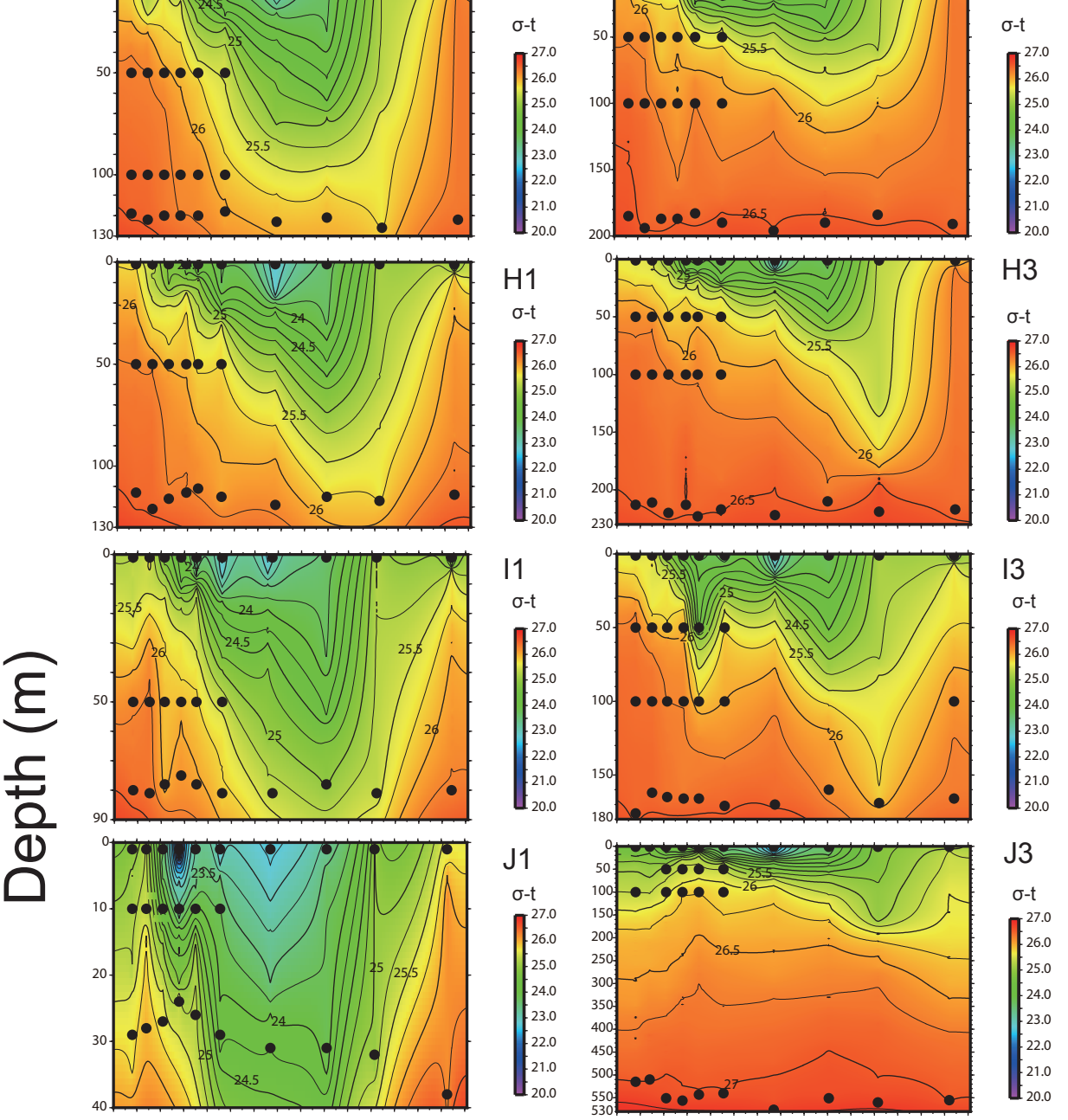

$I 1$
$\sigma-t$
-27.0
26.0
25.0
24.0
23.0
22.0
21.0
20.0

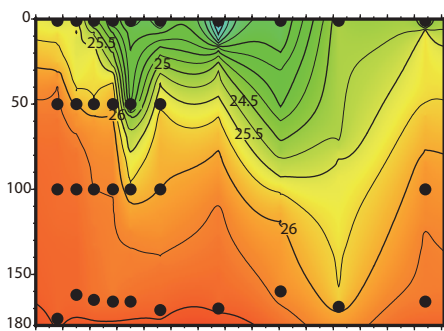

H3

$\sigma-t$
27.0
26.0
25.0
24.0
23.0
22.0
21.0
20.0

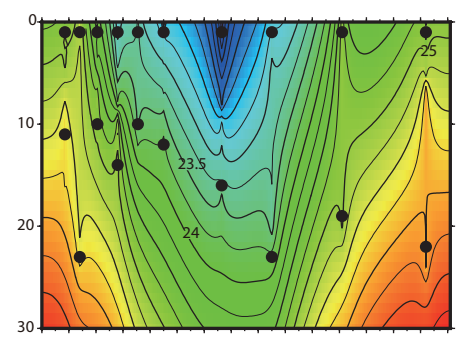

J1
$\sigma-\mathrm{t}$
$\prod_{27.0}^{26.0}$
26.0
25.0
24.0
23.0
22.0
21.0
20.0

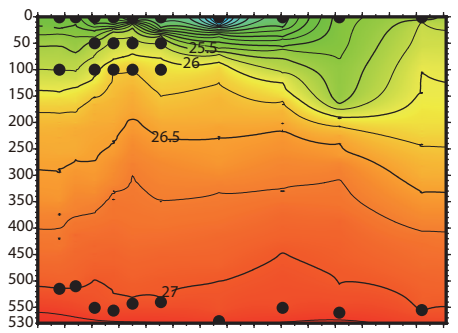

13

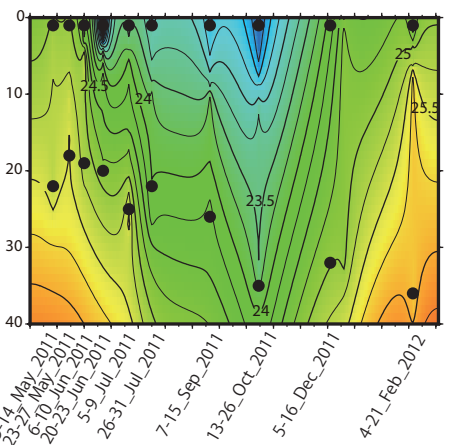

$\mathrm{K} 1$
$\sigma-\mathrm{t}$
27.0
26.0
25.0
24.0
23.0
22.0
21.0
20.0
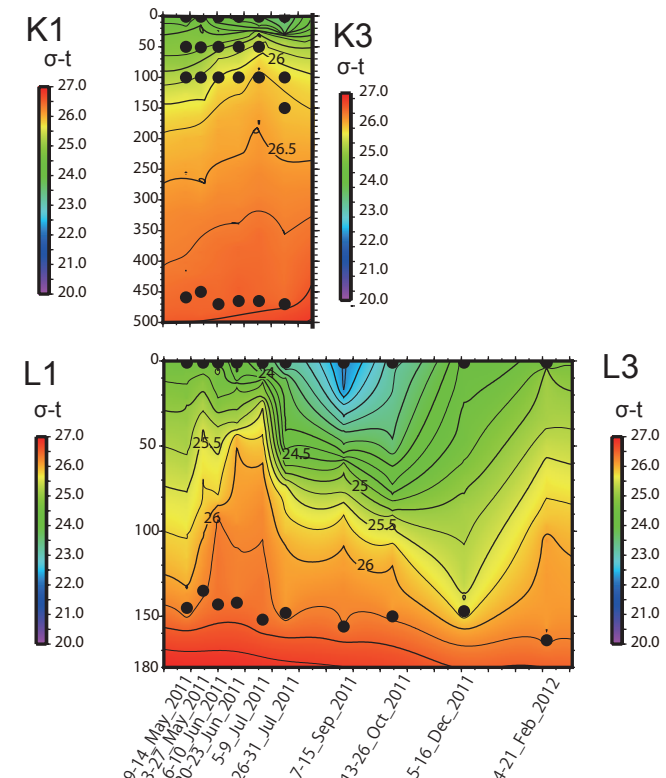

Day

Fig. 6. Continued. 
(Fig. 6). Vertical gradients of $\sigma_{t}$ at each depth indicated that little diapycnal mixing was occurring during Phase 2 .

The $\sigma_{t}$ values in the coastal waters at all the stations near the FDNPP from 27 March 2011 to 7 May 2011 were in the range of $25.5-26.5$ (mean value: $26.1 \pm 0.2$ ) during the Phase 1 survey. The isopycnal lines $\left(\sigma_{t}: 25.5-26.5\right)$ reached bottom depths at Stns. A1-I1, B3, C3, and I3 or depths of about $200 \mathrm{~m}$ at Stns. A3 and D3-H3 by 5-16 December 2011 (Fig. 6). This result indicated that isopycnal surfaces at depths of $\leq 5 \mathrm{~m}$ became gradually deeper with time. To investigate the behavior of radiocesium along isopycnal surfaces during the eight-month sampling period (from 9-14 May to 5-16 December 2011), we plotted the ${ }^{137}$ Cs activities against $\sigma_{t}$ at Stns. D1-G1 and D3-G3 in Fig. 7, the locations of which correspond to stations near the FDNPP during the Phase 1 survey (Fig. 1b). Most of the water samples at $50 \mathrm{~m}$, $100 \mathrm{~m}$, and bottom depths from 9-14 May to 5-16 December 2011 were found to be within the $\sigma_{t}$ range 25.5-26.5, and ${ }^{137} \mathrm{Cs}$ activities decreased in the order $50 \mathrm{~m}>100 \mathrm{~m}$ (or bottom depth for Stn. D1) > bottom depth. There were some exceptions for Stns. D3 (50 and $100 \mathrm{~m}$ depths during 2631 July) and E3 (50 m and $100 \mathrm{~m}$ depths during 5-16 December), where ${ }^{137} \mathrm{Cs}$ activities were relatively low (Fig. 7); this result is probably attributable to the intrusion or mixing of water masses with low $\sigma_{t}$ and low radiocesium activities. At Stn. D3, the $\sigma_{t}$ of the water column at depths of 50-100 m during 26-31 July was different from the $\sigma_{t}$ during the time interval from 9-14 May to 5-9 July because of the presence of a water mass with low $\sigma_{t}$ in the upper $100 \mathrm{~m}$ of the water column. This water mass was present in the upper $50 \mathrm{~m}$ of the water column before 26-31 July (Fig. 6). A similar trend was observed at a depth of $100 \mathrm{~m}$ at Stn. E3 during 5-16 December 2011. On the basis of these results, we concluded that during Phase 1 some of the radiocesiumcontaminated wastewater with $\sigma_{t}$ values of 25.5-26.5 was diluted along isopycnal surfaces, and the depth of the surfaces became greater with time and reached about $200 \mathrm{~m}$ by $5-16$ December. Thus, radiocesium in the coastal waters was diluted along the isopycnal lines during the spring-to-autumn time interval, resulting in a relatively rapid increase in activities of radiocesium at bottom waters and/or $200 \mathrm{~m}$ depth within two months.

\subsection{Temporal variation of ${ }^{90} \mathrm{Sr}$ in the surface water}

Based on the results of the ${ }^{134} \mathrm{Cs}$ and ${ }^{137} \mathrm{Cs}$ radioactivity analyses, we conducted a strontium- 90 survey with a limited number of water samples. These results are summarized in Table 4, together with activities of ${ }^{90} \mathrm{Sr},{ }^{134} \mathrm{Cs}$, and ${ }^{137} \mathrm{Cs}$ and ${ }^{90} \mathrm{Sr} /{ }^{137} \mathrm{Cs}$ activity ratios. Activities of ${ }^{90} \mathrm{Sr}$ ranged from 1.2 to $4.3 \mathrm{mBq} \mathrm{L}^{-1}$. The maximum activity of $4.3 \mathrm{mBq} \mathrm{L}^{-1}$ was observed at Stn. K1 on 14 October 2011 during the 11 WM12 cruise and it was about four times the usual background activity (approximately $1.6 \mathrm{mBq} \mathrm{L}^{-1}$ of the value in the past five years (2006-2010; MEXT, 2010, 2011; Oikawa et al.,

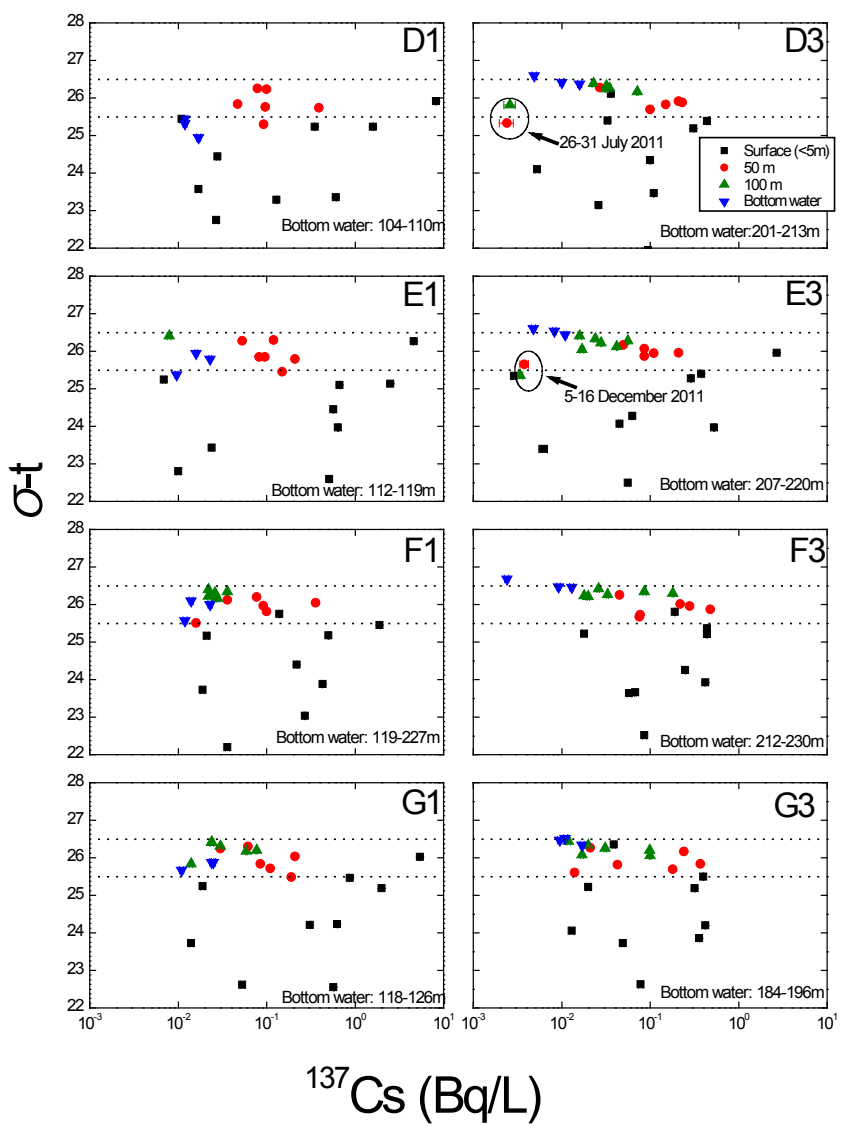

Fig. 7. Relationship between ${ }^{137} \mathrm{Cs}$ concentration and $\sigma_{t}$ at each sampling depth. Dashed lines indicate the $\sigma_{t}$ value range of 25.526.5. Error bars are less than or equal to the size of the symbols.

2013). In addition to the atmospheric releases, the cooling of the reactors with fresh water and seawater, and the release of highly contaminated wastewaters from the damaged reactor resulted in the direct discharges of radionuclides such as ${ }^{90} \mathrm{Sr},{ }^{134} \mathrm{Cs}$ and ${ }^{137} \mathrm{Cs}$ into the Pacific Ocean (Tsumune et al., 2012). During August to November, the activities of ${ }^{90} \mathrm{Sr}$ in seawater samples off Miyagi, Fukushima and Ibaraki were relatively high $\left(2.2-4.3 \mathrm{mBq} \mathrm{L}^{-1}\right)$, suggesting that the FDNPP-derived ${ }^{90} \mathrm{Sr}$ via direct discharge of waste waters was spread widely by the Oyashio and Kuroshio Currents, and/or branches of those two currents. As for the atmospheric fallout, Povinec et al. (2012) have reported that three orders of magnitude lower amounts were released to the atmosphere than in the case of radiocesium in March 2011. Thus, we thought that the contribution of atmospheric radiostrontium input to surface waters is relatively low. Temporal changes in the activity of ${ }^{90} \mathrm{Sr}$ in surface waters are shown in Fig. 8. The activity of ${ }^{90} \mathrm{Sr}$ in surface waters decreased gradually over time and at a given time varied widely between sampling stations. By the end of 2011, the activity of ${ }^{90} \mathrm{Sr}$ in surface waters had reached the background levels recorded before the FDNPP accident. 
Table 4. Hydrographic parameters, activities of ${ }^{90} \mathrm{Sr},{ }^{134} \mathrm{Cs}$, and ${ }^{137} \mathrm{Cs}$. and ${ }^{90} \mathrm{Sr} /{ }^{137} \mathrm{Cs}$ activity ratios in the water samples.

\begin{tabular}{|c|c|c|c|c|c|c|c|c|c|c|c|c|c|c|c|c|c|}
\hline \multirow{3}{*}{$\begin{array}{l}\text { Sampling } \\
\text { station } \\
12\end{array}$} & \multirow{3}{*}{$\begin{array}{l}\text { Cruise } \\
\text { KY11-E03 }\end{array}$} & \multirow{3}{*}{$\begin{array}{l}\text { Sampling } \\
\text { date (JST) } \\
\text { 25-Aug-11 }\end{array}$} & \multirow{3}{*}{$\begin{array}{c}\text { Depth } \\
(\mathrm{m}) \\
3\end{array}$} & \multirow{3}{*}{$\begin{array}{c}\text { Temperature } \\
\left({ }^{\circ} \mathrm{C}\right) \\
25.0\end{array}$} & \multirow{3}{*}{$\begin{array}{c}\text { Salinity } \\
33.75\end{array}$} & \multicolumn{9}{|c|}{ Activity $\left(\mathrm{Bq} \mathrm{L}^{-1}\right)$} & \multirow{2}{*}{\multicolumn{3}{|c|}{$\begin{array}{l}\text { Activity ratio } \\
{ }^{90} \mathrm{Sr} /{ }^{137} \mathrm{Cs}\end{array}$}} \\
\hline & & & & & & \multicolumn{3}{|c|}{${ }^{90} \mathrm{Sr}$} & \multicolumn{3}{|c|}{${ }^{134} \mathrm{Cs}^{*}$} & \multicolumn{3}{|c|}{${ }^{137} \mathrm{Cs}^{*}$} & & & \\
\hline & & & & & & 0.0029 & \pm & 0.0005 & 0.086 & \pm & 0.006 & 0.11 & \pm & 0.006 & 0.026 & \pm & 0.004 \\
\hline 14 & KY11-E03 & 25 -Aug-11 & 4 & 25.5 & 33.82 & 0.0040 & \pm & 0.0005 & 0.094 & \pm & 0.006 & 0.11 & \pm & 0.003 & 0.036 & \pm & 0.004 \\
\hline 20 & KY11-E03 & 26-Aug-11 & 3 & 24.9 & 33.85 & 0.0037 & \pm & 0.0004 & 0.087 & \pm & 0.005 & 0.10 & \pm & 0.003 & 0.037 & \pm & 0.004 \\
\hline $\mathrm{J} 1$ & 11WM11 & 08-Sep-11 & 1 & 22.2 & 33.06 & 0.0032 & \pm & 0.0003 & 0.11 & \pm & 0.01 & 0.12 & \pm & 0.003 & 0.027 & \pm & 0.003 \\
\hline $\mathrm{J} 2$ & 11WM11 & 08-Sep-11 & 1 & 22.7 & 32.89 & 0.0029 & \pm & 0.0003 & 0.11 & \pm & 0.01 & 0.13 & \pm & 0.004 & 0.022 & \pm & 0.002 \\
\hline I1 & 11WM11 & 09-Sep-11 & 1 & 22.5 & 33.13 & 0.0022 & \pm & 0.0004 & 0.084 & \pm & 0.006 & 0.10 & \pm & 0.005 & 0.022 & \pm & 0.004 \\
\hline $\mathrm{L} 1$ & 11WM12 & 13-Oct-11 & 1 & 20.1 & 31.47 & 0.0029 & \pm & 0.0003 & 0.058 & \pm & 0.003 & 0.070 & \pm & 0.002 & 0.041 & \pm & 0.005 \\
\hline $\mathrm{K} 1$ & 11WM12 & $14-O c t-11$ & 1 & 19.8 & 32.26 & 0.0043 & \pm & 0.0004 & 0.050 & \pm & 0.003 & 0.063 & \pm & 0.003 & 0.068 & \pm & 0.008 \\
\hline E5 & 11WM12 & 19-Oct-11 & 1 & 19.8 & 33.83 & 0.0025 & \pm & 0.0003 & 0.056 & \pm & 0.003 & 0.069 & \pm & 0.002 & 0.036 & \pm & 0.004 \\
\hline 10 & KR11-E07 & 30-Nov-11 & 7 & 15.9 & 34.15 & 0.0025 & \pm & 0.0004 & 0.038 & \pm & 0.002 & 0.048 & \pm & 0.001 & 0.052 & \pm & 0.008 \\
\hline 15 & KR11-E07 & 01-Dec-11 & 7 & 16.1 & 34.04 & 0.0022 & \pm & 0.0004 & 0.044 & \pm & 0.002 & 0.056 & \pm & 0.002 & 0.039 & \pm & 0.007 \\
\hline I1 & $11 \mathrm{WM} 13$ & 07-Dec-11 & 1 & 14.0 & 33.78 & 0.0021 & \pm & 0.0004 & 0.014 & \pm & 0.001 & 0.020 & \pm & 0.001 & 0.11 & \pm & 0.02 \\
\hline H1 & $11 \mathrm{WM} 13$ & 07-Dec-11 & 1 & 15.4 & 34.07 & 0.0017 & \pm & 0.0003 & 0.019 & \pm & 0.001 & 0.027 & \pm & 0.001 & 0.063 & \pm & 0.013 \\
\hline G0 & 11WM13 & 09-Dec-11 & 1 & 13.8 & 33.73 & 0.0014 & \pm & 0.0003 & 0.010 & \pm & 0.001 & 0.014 & \pm & 0.001 & 0.10 & \pm & 0.02 \\
\hline G1 & 11WM13 & 09-Dec-11 & 1 & 15.5 & 34.18 & 0.0014 & \pm & 0.0003 & 0.013 & \pm & 0.001 & 0.019 & \pm & 0.001 & 0.074 & \pm & 0.017 \\
\hline $\mathrm{F} 1$ & $11 \mathrm{WM} 13$ & 09-Dec-11 & 1 & 15.2 & 34.01 & 0.0017 & \pm & 0.0003 & 0.015 & \pm & 0.001 & 0.021 & \pm & 0.001 & 0.081 & \pm & 0.016 \\
\hline E1 & 11WM14 & 10-Dec-11 & 1 & 13.7 & 33.70 & 0.0013 & \pm & 0.0002 & 0.005 & \pm & 0.0003 & 0.0069 & \pm & 0.0003 & 0.19 & \pm & 0.03 \\
\hline E3 & 11WM14 & 10-Dec-11 & 1 & 13.7 & 33.82 & 0.0012 & \pm & 0.0002 & 0.0013 & \pm & 0.0002 & 0.0029 & \pm & 0.0002 & 0.41 & \pm & 0.08 \\
\hline
\end{tabular}

* Data on ${ }^{134} \mathrm{Cs}$ and ${ }^{137} \mathrm{Cs}$ at sampling stations where radiostrontium was not detected were excluded in this table. See Table 1 in the Supplement for all the data on radiocesium.
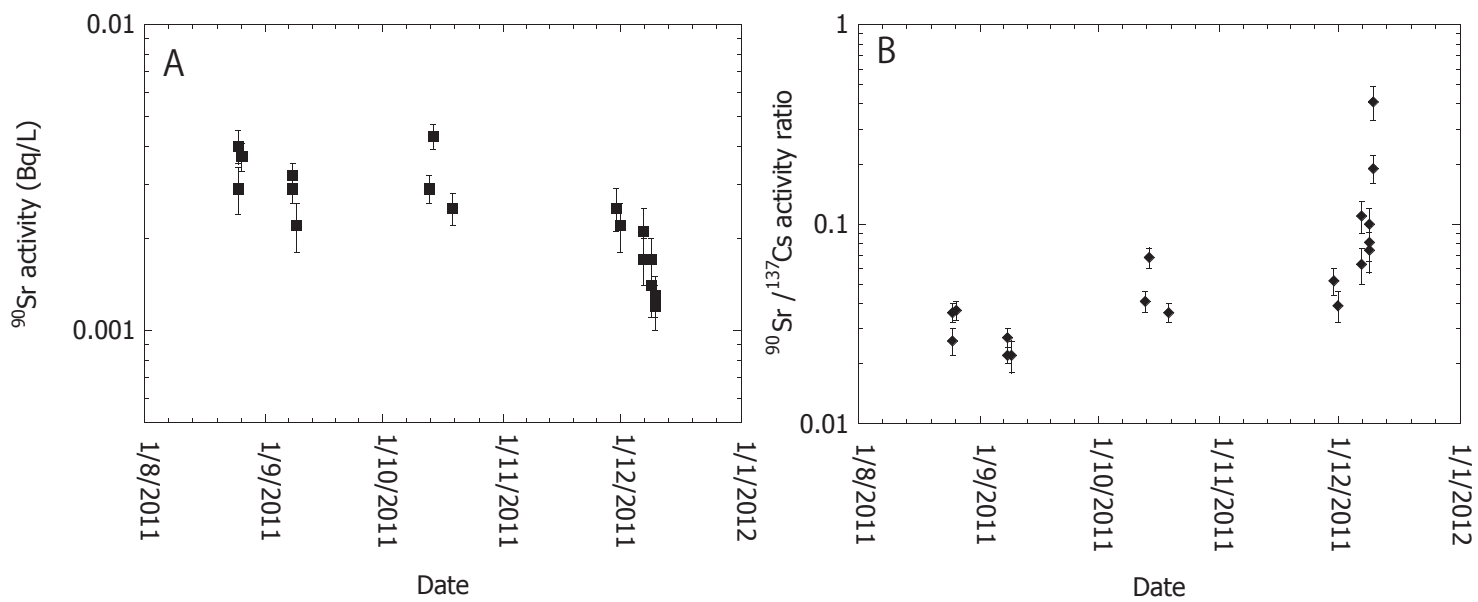

Fig. 8. Temporal variation of activities of ${ }^{90} \mathrm{Sr}$ in the surface water samples (A) and temporal variation of activity ratios of ${ }^{90} \mathrm{Sr}$ to ${ }^{137} \mathrm{Cs}$ in the same surface water samples $(\mathbf{B})$.

Povinec et al. (2012) reported that ${ }^{89} \mathrm{Sr}$ (an indicator of treated water being discharged from the FDNPP) and ${ }^{90} \mathrm{Sr}$ activities in surface water at a site near the FDNPP increased markedly on 5 December 2011 to 140 and $400 \mathrm{~Bq} \mathrm{~L}^{-1}$, respectively, as a result of the release on 4 December 2011 of treated water that contained a considerable amount of radiostrontium. The water had been stored in a tank after removal of radiocesium by absorbers. In our study, however, an increase of radiostrontium activity, which would have provided convincing evidence for the release of radiostrontium from the FDNPP, was not observed in early December 2011. The absence of such evidence was probably due to the fact that the sampling stations where water samples were analyzed for ${ }^{90} \mathrm{Sr}$ measurements were located far from the FDNPP site (Fig. 1c). For example, at Stn. E3 the highest ratio was observed on 10 December 2011. Aoyama et al. (2013) have estimated a zonal speed of the radioactive plume as 1$16 \mathrm{~cm} \mathrm{~s}^{-1}$. If the water mass with high $\mathrm{Sr} / \mathrm{Cs}$ was transported at the maximum speed, the mass could have reached Stn. E3, about $60 \mathrm{~km}$ from the FDNPP, within about 3-4 days.

Thus, while relatively high ${ }^{90} \mathrm{Sr}$ activities after the discharge were not observed, the activity ratio of ${ }^{90} \mathrm{Sr} /{ }^{137} \mathrm{Cs}$ increased by an order of magnitude in early December (Fig. 8b), and that was consistence with the timing of the second direct waste water discharge on 4 December. The Sr/Cs activity ratio can aid in identifying the pathways of $\mathrm{Sr}$ and Cs. This result suggested that the treated water with a high ratio of activity of ${ }^{90} \mathrm{Sr}$ to activity of ${ }^{137} \mathrm{Cs}$ (Povinec et al., 2012) was transported to stations far from the FDNPP, while increased ${ }^{90} \mathrm{Sr}$ activities were not observed. 


\section{Conclusions}

Artificial radionuclides such as ${ }^{131} \mathrm{I},{ }^{134} \mathrm{Cs}$, and ${ }^{137} \mathrm{Cs}$ derived from the FDNPP accident appeared in surface $(\leq 5 \mathrm{~m})$, intermediate, and bottom water samples. However, the amount of ${ }^{131} \mathrm{I}$ in the surface waters decreased abruptly, and no ${ }^{131} \mathrm{I}$ was observed after the end of April 2011.

There was a remarkable variation in ${ }^{137} \mathrm{Cs}$ activities in surface waters during the first 7 months (March-September 2011) of our monitoring study. The distribution patterns in the surface waters suggested that in early May 2011 radiocesium-contaminated water was transported to the north, and then some of the water was advected to the south. The core of the waters with high ${ }^{137} \mathrm{Cs}$ activity persisted at least until July. We believe that these results reflected the influence of currents and the presence of a cyclonic mesoscale eddy. We observed relatively high ${ }^{134} \mathrm{Cs}$ activities derived from the FDNPP accident in subsurface waters. From 9-14 May to 5-16 December 2011, the depth of $\sigma_{t}$ isopycnal surfaces of 25.5-26.5, initially $\leq 5 \mathrm{~m}$, increased with time, an indication that the extension of isopycnal surfaces to greater depth with time could be an important mechanism for transporting radiocesium downward in coastal waters. During 421 February 2012, we observed the formation of a vertically homogeneous water mass, probably a consequence of vertical mixing processes during the winter and the result was nearly constant activities of radiocesium throughout the water column from the surface to bottom $(\sim 200 \mathrm{~m})$ at each station.

Fukushima-derived ${ }^{90} \mathrm{Sr}$ was found in surface waters collected at sampling stations from mid-August 2011 to midDecember 2011. The activities of ${ }^{90} \mathrm{Sr}$ at a given time varied widely between sampling stations. The activities of ${ }^{90} \mathrm{Sr}$ in the surface waters decreased slowly over time and by the end of December 2011 had reached the background level recorded before the FDNPP accident.

\section{Supplementary material related to this article is available online at: http://www.biogeosciences.net/10/ 5031/2013/bg-10-5031-2013-supplement.pdf.}

Acknowledgements. We thank Katsutoshi Kido and Kiriko Miyamoto for helpful discussions, and Sachiko Kiuchi for technical assistance. We also thank the captains and crew of research vessels of the JAMSTEC and Nippon Kaiyo Co. Ltd. for their help in the sampling. The marine environmental radioactivity survey is part of a research project contracted from the Japanese Ministry of Education, Culture, Sports, Science and Technology.

Edited by: M. Aoyama

\section{References}

Aoyama, M., Tsumune, D., Uematsu, M., Kondo, F., and Hamajima, Y.: Temporal variation of ${ }^{134} \mathrm{Cs}$ and ${ }^{137} \mathrm{Cs}$ activities in surface water at stations along the coastline near the Fukushima Daiichi Nuclear Power Plant accident site, Japan, Geochem. J., 46, 321-325, 2012.

Aoyama, M., Uematsu, M., Tsumune, D., and Hamajima, Y.: Surface pathway of radioactive plume of TEPCO Fukushima NPP1 released ${ }^{134} \mathrm{Cs}$ and ${ }^{137} \mathrm{Cs}$, Biogeosciences, 10, 30673078, doi:10.5194/bg-10-3067-2013, 2013.

Buesseler, K., Aoyama, M., and Fukasawa, M.: Impacts of the Fukushima nuclear power plants on marine radioactivity, Environ. Sci. Technol. 45, 9931-9935, 2011.

Buesseler K. O., Jayne, S. R., Fisher, N. S., Rypina, I. I., Baumann, H., Baumann, Z., Breier, C. F., Douglass, E. M., George, J., Macdonald, A. M., Miyamoto, H., Nishikawa, J., Pike, S. M., and Yoshida, S.: Fukushima-derived radionuclides in the ocean and biota off Japan, P. Natl. Acad. Sci., 109, 5984-5988, 2012.

Comans, R. N. J., Haller, M., and DePreter, P.: Sorption of cesium on illite: non-equilibrium behavior and reversibility, Geochim. Cosmochim. Ac., 55, 433-440, 1991.

Fowler, S.,W., Buat-Menard, P., Yokoyama, Y., Ballestra, S., Holm, E., and Nguyen, H. V.: Rapid removal of Chernobyl fallout from Mediterranean surface waters by biological activity, Nature 329, 56-58, 1987.

Honda, M. C., Imai, K., Nojiri, Y., Hoshi, F., Sugawara, T., and Kusakabe, M.: The biological pump in the northwestern North Pacific based on fluxes and major components of particulate matter obtained by sediment-trap experiments (1997-2000), DeepSea Res. Pt. II, 49, 5595-5625, 2002.

Honda, M. C., Aono, T., Aoyama, M., Hamajima, Y., Kawakami, H., Kitamura, M., Masumoto, Y., Miyazawa, Y., Takigawa, M., and Saino, T.: Dispersion of artificial caesium-134 and -137 in the western North Pacific one month after the Fukushima accident, Geochem. J., 46, 1-9, 2012.

IAEA (International Atomic Energy Agency): Sediment distribution coefficients and concentration factors for biota in the marine environment, Technical Report Series no. 422, IAEA, Vienna, 195, 2004.

Inomata, Y., Aoyama, M., and Hirose, K.: Analysis of 50-y record of surface ${ }^{137} \mathrm{Cs}$ concentrations in the global ocean using the HAM-global database, J. Environ. Monitor. 11 116-125, 2009.

Inoue, M., Kofuji, H., Hamajima, Y., Nagao, S., Yoshida, K., and Yamamoto, M.: ${ }^{134} \mathrm{Cs}$ and ${ }^{137} \mathrm{Cs}$ activities in coastal seawater along Northern Sanriku and Tsugaru Strait, northeastern Japan, after Fukushima Dai-ichi Nuclear Power Plant accident, J. Environ. Radioact., 111, 116-119, 2012.

JMA (Japan Meteorological Agency): Report (No.14) of the 2011 off the Pacific coast of Tohoku Earthquake, 13th March 2011, 2011a, (in Japanese).

JMA (Japan Meteorological Agency): Report (No.15) of the 2011 off the Pacific coast of Tohoku Earthquake, 13th March 2011, 2011b, (in Japanese).

Kaeriyama, H., Watabe, T., and Kusakabe, M.: ${ }^{137}$ Cs concentration in zooplankton and its relation to taxonomic composition in the western North Pacific Ocean, J. Environ. Radioact., 99, 1838$1845,2008$. 
Kaeriyama, H., Anbe, D., Shigenobu, Y., Fujimoto, K., Ono, T., Tadokoro, K., Okazaki, Y., Narimatsu, Y., and Watanbe, A.: Concentration ratio of radio Cs derived from the Fukushima Daiichi nuclear power plant accident for zooplankton in seawater off Fukushima and Miyagi prefectures, Japan, Fall meeting of the Oceanographic Society of Japan, Shimizu, Shizuoka, Japan, 13-17 September 2012, 407, 2012.

Kawamura, H., Kobayashi, T., Furuno, A., In, T., Ishikawa, Y., Nakayama, T., Shima, S., and Awaji, T.: Preliminary numerical experiments on oceanic dispersion of ${ }^{131} \mathrm{I}$ and ${ }^{137} \mathrm{Cs}$ discharged into the ocean because of the Fukushima Daiichi Nuclear Power Plant disaster, J. Nucl. Sci. Technol., 48, 1349-1356, 2011.

Kusakabe, M., Ku, T. L., Harada, K., Taguchi, K., and Tsunogai, S.: Chernobyl radioactivity found in mid-water sediment interceptors in the N. Pacific and Bering Sea, Geophys. Res. Lett., 15, 44-47, 1988.

Kusakabe, M., Oikawa, S., Takata, H., and Misonoo, J.: Spatiotemporal distributions of Fukushima-derived radionuclides in nearby marine surface sediments, Biogeosciences, 10, 50195030, doi:10.5194/bg-10-5019-2013, 2013.

Matsuura, H., Isoda,Y., Kuroda, H., Kuma, K., Saitoh, Y., Kobayashi, N., Aiki, T., Wagawa, T., Yabe, I., and Hoshiba, Y.: Water mass modification process of the passage-flow waters through the Tsugaru Strait. Umi to Sora, 83, 21-35, 2007 (in Japanese with English abstract).

MEXT (Ministry of education, Culture, Sports, Science and Technology): Radioactivity Measurement Series No.7, available at: http://www.kankyo-hoshano.go.jp/series/lib/No7.pdf (last access: 8 May 2013), 1992 (in Japanese).

MEXT: Report of Comprehensive Monitoring Plan for Radioactivity in the Marine Environments, March 2010 (in Japanese).

MEXT: Report of Comprehensive Monitoring Plan for radioactivity in the Marine Environments, March 2011 (in Japanese).

Momoshima, N., Sugihara, S., Ichikawa, R., and Yokoyama, H.: Atmospheric radionuclides transported to Fukuoka, Japan remote from the Fukushima Dai-ichi nuclear power complex following the nuclear accident, J. Environ. Radioact., 111, 28-32, 2012.

NERH (Nuclear Emergency Response Headquarters), Government of Japan: Report of Japanese Government to the IAEA Ministerial Conference on Nuclear Safety - The Accident at TEPCO's Fukushima Nuclear Power Stations, 2011.
Oikawa, S., Watabe, T., Inatomi, N., Isoyama, N., Misonoo, J., Suzuki, C., Nakahara, M., Nakamura, R., Morizono, S., Fujii, S., Hara, T., and Kido, K.: Plutonium isotopes concentration in seawater and bottom sediment off the Pacific coast of Aomori sea area during 1991-2005, J. Environ. Radioact., 102, 302-310, 2011.

Oikawa, S., Watabe, T., Takata, H., Suzuki, C., Nakahara, M., and Misonoo, J: Progress in the field of marine environmental radioactivity analysis for an offshore fishery monitoring purposes, Bunseki Kagaku, 62, 455-474, 2013.

Otosaka, S. and Kobayashi, T.: Sedimentation and remobilization of radiocesium in the coastal area of Ibaraki, $70 \mathrm{~km}$ south of the Fukushima Dai-ichi Nuclear Power Plant, Environ. Monitor. Assess., 185, 5419-5433 doi:10.1007/s10661-012-2956-7, 2012.

Povinec, P. P., Hirose, K., and Aoyama, M.: Radiostrontium in the western North Pacific: characteristics, behavior and the Fukushima impact, Environ. Sci. Technol., 46, 10356-10363, 2012.

Sakuma, H. and Kawamura, K.: Structure and dynamics of water on $\mathrm{Li}^{+}{ }_{-}, \mathrm{Na}^{+}{ }_{-}, \mathrm{K}^{+}-, \mathrm{Cs}^{+}{ }_{-}, \mathrm{H}_{3} \mathrm{O}^{+}$-exchanged muscovite surfaces: a molecular dynamics study, Geochim. Cosmochim. Ac., 75, 63$81,2011$.

Sasaki, K. and Hiroe, Y.: Mechanism of nutrient supply to warmcore ring off Sanriku, Japan, J. Oceanogr., 58, 683-690, 2002.

Takata, H., Aono, T., Tagami, K., and Uchida, S.: Sediment-water distribution coefficients of stable elements in four estuarine areas in Japan, J. Nucl. Sci. Technol., 47, 111-122, 2010.

Tsumune, D., Tsubono, T., Aoyama, M., and Hirose, K.: Distribution of oceanic ${ }^{137} \mathrm{Cs}$ from the Fukushima Dai-ichi Nuclear Power Plant simulated numerically by a regional ocean model, J. Environ. Radioact., 111, 100-108, 2012.

UNSCEAR (United Nations Scientific Committee on the Effects of Atomic Radiation): Sources and Effects of Ionizing Radiation, United Nations Scientific Committee on the Effects of Atomic Radiation, New York, USA, 2000.

Yoshie, N., Yamanaka, Y., Kishi, J. M., and Saito, H.: One dimensional ecosystem model simulation of the effects of vertical dilution by the winter mixing on the spring diatom bloom, J. Oceanogr., 59, 563-571, 2003. 